\title{
BEHAVIOUR AND DESIGN OF HEXAGONAL CONCRETE- FILLED STEEL TUBULAR SHORT COLUMNS UNDER AXIAL COMPRESSION
}

\author{
M. F. HASSANEIN", V. I. PATEL ${ }^{*}, 1$, M. BoCK ${ }^{\wedge}$

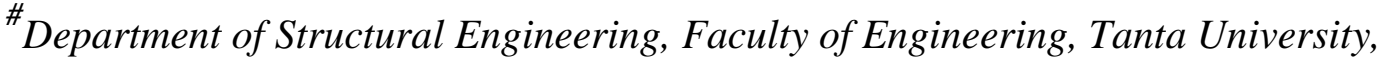 \\ Tanta, Egypt \\ ${ }^{*}$ School of Engineering and Mathematical Sciences, Bendigo, VIC 3552, Australia \\ ${ }^{\wedge}$ Department of Civil Engineering, University of Wolverhampton, Wolverhampton WV1 1LY, \\ $U K$
}

\section{Abstract}

Concrete-filled steel tubular (CFST) columns have frequently been utilised in the construction of mid-rise and high-rise buildings as they offer smaller cross-sectional size to load carrying capacity ratio than ordinary reinforced concrete or steel solutions. The steel tube component of CFST columns can be shaped into different forms to further increase its strength and this article focuses on hexagonal CFST short columns in compression. Firstly, the literature is revised and it was found that the available experiments on the hexagonal columns cover relatively limited hexagonal dimensions and material properties. Additionally, existing design models were observed to be inaccurate for certain diameter-to-thickness ( $D / t$ ) ratios of the columns. Accordingly, this paper intends to widen the available pool of data and proposes a new design model to design hexagonal CFST short columns in compression. This is made herein through comprehensive finite element (FE) models by using Abaqus software, carefully validated against experimental results and subsequent parametric studies covering a wide range of hexagonal dimensions of regular cross-section (circular-like). The effect of various $D / t$ ratios, material steel grades and concrete compressive strengths $\left(f_{c}^{\prime}\right)$ on both the behaviour and strength of the hexagonal CFST short columns is investigated. Based on observations made and conclusions drawn upon analysing

\footnotetext{
${ }^{1}$ Corresponding author: Tel.: +61 35444 7488; Email: v.patel@latrobe.edu.au (V. I. Patel)
} 
numerical data generated, a new design model is presented which provides better strengths compared with available design models and with accurate predictions for the full range of $D / t$ ratios.

\section{KEYWORDS}

Concrete-filled steel tubular columns; Hexagonal section; Regular Hexagon; Axial compressive strength; Finite element analysis; Stub columns; Design model.

\section{INTRODUCTION}

Structural columns made from two different materials or elements such as structural steel and concrete behave compositely. Concrete encased structural steel sections and concrete-filled steel tubular (CFST) sections are the main cross-sectional types of composite columns [1-8]. Concrete-filled steel tubular (CFST) columns result from filling hollow steel tubes with concrete, with the idea traced back to 1879 when the piers of the Severn Railway Bridge in the UK, where made of CFST columns [8] to resist high railway loads. Compared with concrete encased structural steel columns, the steel tubes act as a formwork for casting the in situ concrete and thus it eliminates the need of additional formwork and leads to a fast track construction [1-8]. Furthermore, it does not need additional reinforcement. Therefore, CFST columns have been increasingly employed as columns in medium and high-rise buildings [23], bridge and large span buildings [2] and as piers [2, 9-10].

Circular and rectangular (including square) CFST columns depicted in Fig. 1 are the most commonly used cross-sectional shapes in modern construction. Examples of circular CFST columns [11] are those used in the new VDEh-building in Dusseldorf, Germany, while square CFST columns [2] were utilised in Ruifeng International Commercial Building built in 
Hanzhou, China. Circular CFST columns (Fig. 1(a)) own more resistance and ductility compared with their rectangular counterpart columns (Fig. 1(b)). This is because the circular section provides a substantial amount of confinement to the concrete core in CFST columns, whereas this effect is tiny in the case of rectangular hollow sections [7]. Accordingly, the concrete strength increases due to the lateral restrain provided by the surrounding circular steel tube. On the other hand, the ease of connections makes the latter columns preferable in framed structures. Accordingly, circular and rectangular CFST columns were extensively investigated in literature $[2,8]$. However, the choice of the cross-section of the CFST column for a specific project not only depends on the column efficiency, material availability, cost and construction methods, but also on architectural and aesthetic criteria; see for example Ref. [4]. Some cross-sectional shapes that have also been suggested, studied and utilised in practice for aesthetical and architectural purposes are the elliptical [8] and the polygonal [12] shapes, as also presented in Fig. 1, despite their reduced confinement effect compared with the circular hollow sections.

One of the CFST cross-sections that have recently gained significant attention is the hexagonal shape used in Gaoyin Financial Building and Z15 tower in China. Such columns with hexagonal shape were designed to make them easier to connect with the beams of the structural skeleton of the tower [13]. Research on hexagonal CFST available in the literature is relatively scarce and although design approaches have been proposed for various CFST shapes, their suitability for designing the hexagonal CFST requires further investigation. In 2013, Yu et al. [12] suggested a unified design equation to determine the ultimate axial strength for both the circular and regular polygonal CFST columns. This equation was verified for application to octagonal CFST columns using experimental results reported by Tomii [14] but no assessment exists for the hexagonal shape to date. Evirgen et al. [15] 
conducted experiments on CFST columns of regular hexagonal-shaped cross-sections with small dimensions (see Fig. 2(a)) under axial compression. The behaviour of the hexagonal CFST columns [15] was carefully analysed but their ultimate test strengths were not compared with predictions of the design equation proposed by $\mathrm{Yu}$ et al. [12]. More recently, two experimental investigations were conducted on the behaviour and strength of largediameter hexagonal CFST columns in China by $\mathrm{Xu}$ et al [13] and Ding et al. [16]. The investigation presented in $\mathrm{Xu}$ et al. [13] focused on dual-axisymmetric cross-sections in compression (Fig. 2(b)) and concluded that the strengths of such sections are suitably predicted by the equations given in EN 1994-1-1 [17] for rectangular CFST short columns as both of them were observed to have similar confinement effects. Regarding research by Ding et al. [16], they presented the results of an experimental investigation on regular hexagonal shape (Fig. 2(a)) and derived a new design approach that takes into account concrete confinement effects. Additionally, Ding et al. [16] observed that the confinement mechanism in the hexagonal CFST columns is different compared to circular CFST columns. While the circular steel section provides continuous confinement all over the perimeter (see Fig. 2(c)), confinement effects on regular hexagonal CFST were observed to extend from the corner areas of the hexagon to the centre of the concrete core and the length of unconfined parts, as shown in Fig. 2(c), was approximately found to be $60 \%$ of the side length of the regular hexagon [16] which leaves a 33\% of the total concrete core area unconfined. Accordingly, even if the regular hexagonal section is closer in shape to the circular section than to the rectangular section; the circular section situation cannot be used as a benchmark in the strength calculation of this type of CFST columns. This has recently been confirmed by Ding et al. [16] through proposing a new design model for such hexagonal columns. 


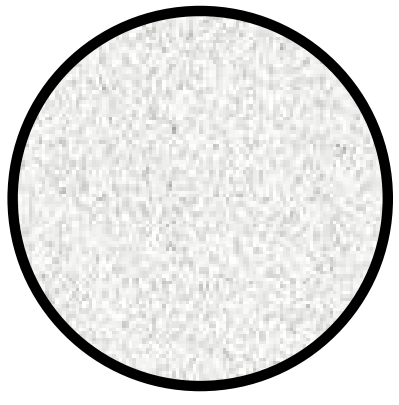

(a) Circular

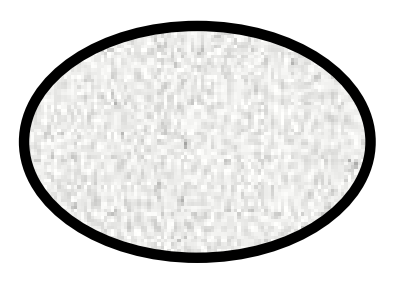

(c) Elliptical

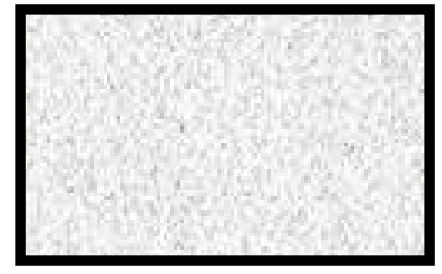

(b) Rectangular

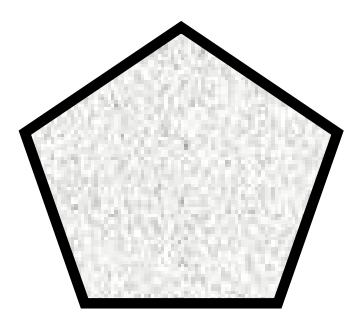

(d) Polygonal

Fig. 1: Different cross-sectional shapes for CFST columns

In order to complement the few investigations above mentioned and contribute to developing depth understanding of the behaviour of CFST, this article investigates the behaviour and strength of hexagonal CFST short columns in compression on a numerical and analytical basis. Focus has been given to the regular shape as, to the authors' experience; it bears higher axial compression resistance than its dual-axisymmetric counterpart. This is because a regular steel tube shape resembles more closely a circular shape which evenly confines the concrete throughout the perimeter hence enhancing the strength and ductility of the composite tube. Firstly, this article presents a comprehensive assessment of all existing design methods for hexagonal CFST by comparing predicted strengths against all tests found in the literature. Secondly, a comprehensive finite element (FE) model is developed, calibrated and validated against experiments by using Abaqus [18]. Parametric studies are subsequently performed to 
further investigate the effects of key material and geometrical parameters on the behaviour and strength of hexagonal CFST short columns. Within the parametric study, fully-effective hexagonal tubular sections with a wide range of material properties and diameter-to-thickness ratios $\mathrm{D} / \mathrm{t}$ are considered to cover ratios that have never been investigated before. The main factors affecting the behaviour of regular hexagonal CFST short columns are presented, carefully examined and a new model allowing for confinement effects is proposed. The numerical strengths of the hexagonal CFST short columns achieved by the models are also analysed and compared against the available design models assessed at the first point of this investigation for comparison purposes. In sight into such design methods is given in the next section.

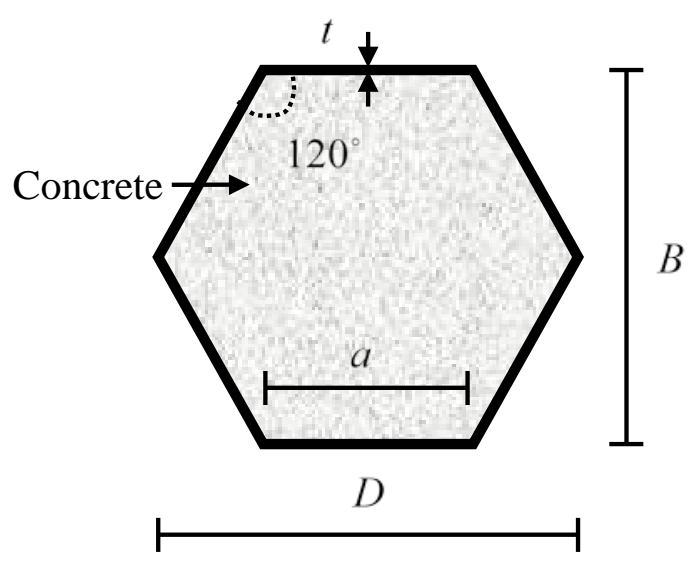

(a) Regular cross-section

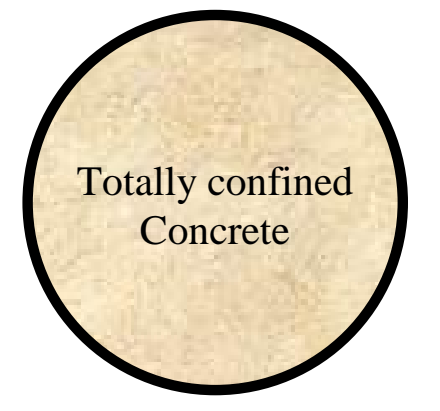

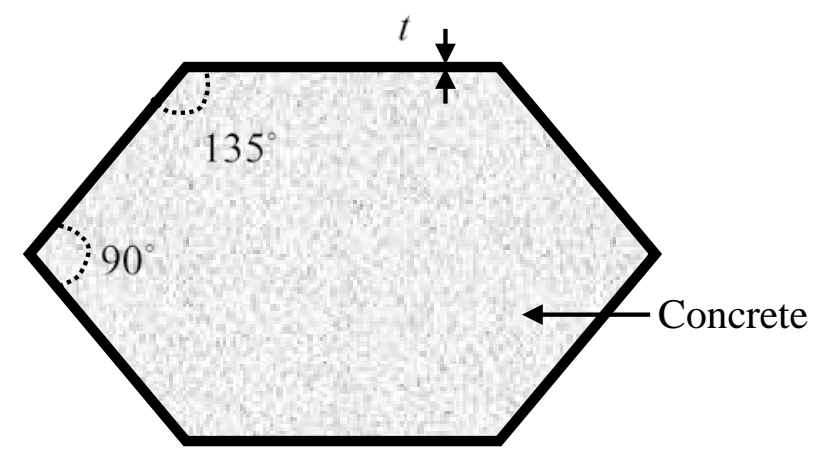

$D$

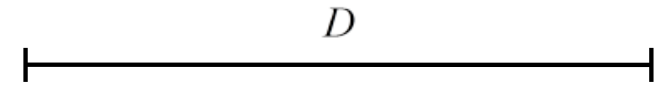

(b) Dual-axisymmetric cross-section

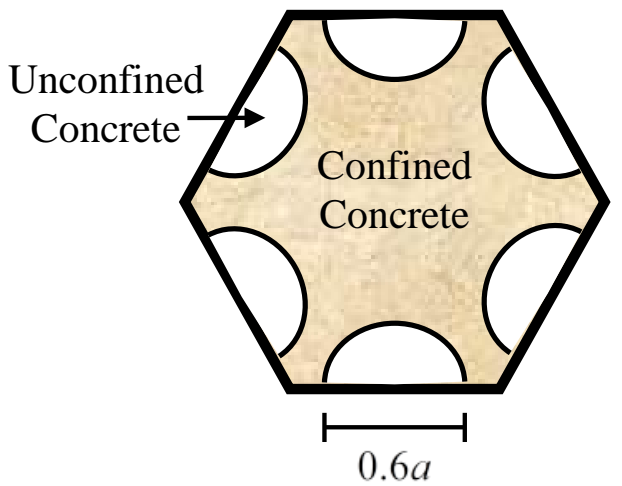

(c) Confined concrete in circular and regular hexagonal cross-sections [7, 16]

Fig. 2: Types of hexagonal CFST columns and confined concrete 


\section{ASSESSMENT OF AVAILABLE DESIGN METHODS}

In this section, the accuracy of available design methods to determine the resistance of regular hexagonal CFST short columns in compression is assessed by comparing their predictions with all experimental data collated from literature [15-16]. Table 1 lists the details of such tests including the specimens' diameter $D$, thickness $t$, experimental strength $P_{u l, \text { Exp }}$, the average yield strength measured from the tensile coupon tests $f_{y}$ and the experimental concrete compressive strengths $\left(f_{c}^{\prime}\right)$ as reported in Refs. [15-16]. The minimum and maximum values of the geometrical dimensions, ratios and material properties are given at the bottom of the table, from which it can be noticed that the available experiments on hexagonal CFST columns cover relatively a limited number of D/t ratios.

To date, there are three equations for determining the strength of hexagonal short CFST columns in compression. The first equation $\left(P_{u l, Y u}\right)$ considered in this assessment is that suggested by $\mathrm{Yu}$ et al. [12] which is a unified equation applicable to both circular and polygonal CFST columns. The second equation is that given in EN 1994-1-1 [17] for rectangular CFST short columns modified by Xu et al. [13] for application to hexagonal cross-sections $\left(P_{u l, R e c, E C 4}\right)$. And finally, the third method is that proposed by Ding et al. [16] ( $\left.P_{u l, D i n g}\right)$ which allows for confinement effects of the outer hexagonal steel tube to the inner concrete core through incorporation of a confinement coefficient factor applied to the steel contribution. In the following sub-sections, a brief summary of these design methods is given, followed by a comparison and discussion of their predictions. 
Table 1: Details of the experimental test specimens of the regular hexagonal CFST short columns

\begin{tabular}{|c|c|c|c|c|c|c|c|}
\hline Specimens & Ref. & $\begin{array}{c}D \\
{[\mathrm{~mm}]}\end{array}$ & $\begin{array}{c}t \\
{[\mathrm{~mm}]}\end{array}$ & $\frac{D}{t}$ & $\begin{array}{c}f_{y} \\
{[\mathrm{MPa}]}\end{array}$ & $\begin{array}{c}f_{c}^{\prime} \\
{[\mathrm{MPa}]}\end{array}$ & $\begin{array}{c}P_{u l, E x p} \\
{[\mathrm{kN}]}\end{array}$ \\
\hline HS1510 & \multirow{12}{*}{ [15] } & 150 & 1.50 & 100 & 255 & 13.3 & 398 \\
\hline HS1520 & & 150 & 1.50 & 100 & 255 & 26.0 & 518 \\
\hline HS1530 & & 150 & 1.50 & 100 & 255 & 35.3 & 684 \\
\hline HS3010 & & 150 & 3.00 & 50 & 255 & 13.3 & 632 \\
\hline HS3020 & & 150 & 3.00 & 50 & 255 & 26.0 & 700 \\
\hline HS3030 & & 150 & 3.00 & 50 & 255 & 35.3 & 826 \\
\hline HS5010 & & 150 & 5.00 & 30 & 255 & 13.3 & 1090 \\
\hline HS5020 & & 150 & 5.00 & 30 & 255 & 26.0 & 1184 \\
\hline HS5030 & & 150 & 5.00 & 30 & 255 & 35.3 & 1247 \\
\hline HS8010 & & 150 & 8.00 & 18.75 & 255 & 13.3 & 1624 \\
\hline HS8020 & & 150 & 8.00 & 18.75 & 255 & 26.0 & 1697 \\
\hline HS8030 & & 150 & 8.00 & 18.75 & 255 & 35.3 & 1757 \\
\hline HST1-A & \multirow{8}{*}{ [16] } & 392 & 3.73 & 105 & 311 & 32.2 & 4947 \\
\hline HST1-B & & 396 & 3.71 & 107 & 311 & 32.2 & 4618 \\
\hline HST2-A & & 392 & 5.78 & 68 & 321 & 32.2 & 6001 \\
\hline HST2-B & & 396 & 5.96 & 66 & 321 & 32.2 & 6041 \\
\hline HST3-A & & 394 & 3.72 & 106 & 311 & 49.0 & 6827 \\
\hline HST3-B & & 396 & 3.76 & 105 & 311 & 49.0 & 6803 \\
\hline HST4-A & & 398 & 5.89 & 68 & 321 & 49.0 & 7079 \\
\hline HST4-B & & 392 & 5.81 & 67 & 321 & 49.0 & 7289 \\
\hline \multicolumn{2}{|l|}{ Min } & 150 & 1.50 & 18.75 & 255 & 13.3 & \\
\hline \multicolumn{2}{|c|}{ Max } & 398 & 8.00 & 106 & 321 & 49.0 & \\
\hline
\end{tabular}

\subsection{Design model by Yu et al. [12]}

Yu et al. [12] derived a generalised formula for predicting the ultimate axial strength of circular and polygonal CFST short columns subjected to axial loading $\left(P_{u l, Y u}\right)$. This model is given by Eq. (1), where $\xi$ is the confinement factor determined as $\xi=f_{s} A_{s} / f_{c k} A_{c}, A_{s}$ and $A_{c}$ are the cross-sectional areas of steel and concrete, respectively, $f_{c k}$ represents the characteristic strength value for the concrete, calculated as 0.67 times the cubic compressive strength $\left(f_{c u}\right)$ and $k_{n}=\left(n^{2}-4\right) /\left(n^{2}+20\right)$, where $n$ denotes the number of sides of the polygonal cross-section (i.e. six in case of hexagon).

$P_{u l, Y u}=\left(1+0.5 k_{n} \frac{\xi}{1+\xi}\right)\left(f_{y} A_{s}+f_{c k} A_{c}\right)$ 


\subsection{Design model given in EN 1994-1-1 [17] examined by Xu et al. [13]}

According to Xu et al. [13], the strengths $\left(P_{u l, R e c, E C 4}\right)$ of hexagonal CFST short columns, can be adequately predicted by the design method given in EN 1994-1-1 [17] for rectangular CFST short columns. The model superimposes the contribution of the external steel tube on the concrete core term as given in Eq. (2), where $f_{c}^{\prime}$ is the unconfined cylindrical strength of the concrete and $f_{y}$ is the yield strength of the steel.

$P_{u l, \operatorname{Re}, E C 4}=f_{c}^{\prime} A_{c}+f_{y} A_{s}$

\subsection{Design model by Ding et al. [16]}

Ding et al. [16] derived a new equation to determine the compression strength $\left(P_{u l, \text { Ding }}\right)$ of hexagonal CFST short columns as given by Eq. (3) which follows the conceptual philosophy of EN 1994-1-1[17] but incorporates a confinement factor on the contribution of the external steel tube term. A suitable value for such factor of 1.3 was proposed in [16].

$P_{u l, \text { Ding }}=f_{c}^{\prime} A_{c}+1.3 f_{y} A_{s}$

\subsection{Comparison and discussion}

The predictions of the three above mentioned design equations for regular hexagonal CFST short columns $P_{u l, Y u}$ [12], $P_{u l, \operatorname{Rec}, E C 4}[13,17]$ and $P_{u l, D i n g}[16]$ are compared against experimental results $P_{u l, E x p}$ from literature [15-16] in Table 2, where the specimens are sorted by the diameter-to-thickness $D / t$ ratio of the CFST column. The mean value of the predicted-to-experimental ratios for $P_{u l, Y u}$ and $P_{u l, R e c, E C 4}$ approaches are both 0.81, though the first approach yields lower scatter than the second one with COV of 0.094 and 0.159 , 
respectively. The closest value to the unity, therefore most efficient design, is achieved by $P_{u l, D i n g}$ with a mean value of 0.91 , however, there are a few unsafe predictions $\left(P_{u l} / P_{u l, E x p}>1\right.$ ) associated with small-diameter specimens tested by Evirgen et al. [15]. The relationship between the predicted to experimental $P_{u l} / P_{u l, E x p}$ ratio and the $D / t$ ratios for the three design equations is given in Fig. 3 where it is observed inconsistency over the spectrum of $D / t$ ratios as the best data fit model is other than a parallel line to the horizontal axis. Hence, a new design model should be proposed to more accurately and consistently predict the strength of regular hexagonal CFST short columns. To do so, a first start point is to extend the existing pool of available data. This is numerically undertaken in the next sections by using carefully validated FE models.

Table 2: Comparison of relative design strengths of the experimental strengths of hexagonal CFST short columns

\begin{tabular}{|c|c|c|c|c|c|c|c|c|}
\hline Specimens & Ref. & $\begin{array}{l}P_{u l, Y u} \\
{[\mathrm{kN}]}\end{array}$ & $\begin{array}{c}P_{u l, \operatorname{Re} c, E C 4} \\
{[\mathrm{kN}]}\end{array}$ & $\begin{array}{c}P_{u l, \text { Ding }} \\
{[\mathrm{kN}]}\end{array}$ & $\frac{P_{u l, Y u}}{P_{u l, E x p}}$ & $\frac{P_{u l, \operatorname{Re} c, E C 4}}{P_{u l, \text { Exp }}}$ & $\frac{P_{u l, \text { Ding }}}{P_{u l, \text { Exp }}}$ & $\frac{P_{u l, \text { Sug }}}{P_{u l, \text { Exp }}}$ \\
\hline HS8010 & [15] & 1090 & 908 & 1134 & 0.67 & 0.56 & 0.70 & 0.92 \\
\hline HS8020 & [15] & 1207 & 1056 & 1282 & 0.71 & 0.62 & 0.76 & 1.00 \\
\hline HS8030 & [15] & 1292 & 1164 & 1390 & 0.74 & 0.66 & 0.79 & 0.87 \\
\hline HS5010 & [15] & 751 & 650 & 794 & 0.69 & 0.60 & 0.73 & 0.89 \\
\hline HS5020 & [15] & 878 & 811 & 955 & 0.74 & 0.69 & 0.81 & 0.87 \\
\hline HS5030 & [15] & 972 & 930 & 1074 & 0.78 & 0.75 & 0.86 & 0.89 \\
\hline HS3010 & [15] & 517 & 471 & 559 & 0.82 & 0.75 & 0.89 & 0.95 \\
\hline HS3020 & [15] & 652 & 642 & 730 & 0.93 & 0.92 & 1.04 & 0.90 \\
\hline HS3030 & [15] & 750 & 768 & 855 & 0.91 & 0.93 & 1.04 & 1.04 \\
\hline HST2-B & [16] & 5015 & 5024 & 5606 & 0.83 & 0.83 & 0.93 & 1.12 \\
\hline HST4-B & [16] & 6024 & 6476 & 7038 & 0.83 & 0.89 & 0.97 & 1.03 \\
\hline HST4-A & [16] & 6207 & 6674 & 7251 & 0.88 & 0.94 & 1.02 & 1.00 \\
\hline HST2-A & [16] & 4869 & 4889 & 5447 & 0.81 & 0.81 & 0.91 & 1.13 \\
\hline HS1510 & [15] & 337 & 334 & 379 & 0.85 & 0.84 & 0.95 & 1.11 \\
\hline HS1520 & [15] & 477 & 512 & 557 & 0.92 & 0.99 & 1.08 & 0.92 \\
\hline HS1530 & [15] & 580 & 643 & 687 & 0.85 & 0.94 & 1.00 & 0.97 \\
\hline HST1-A & [16] & 4033 & 4263 & 4614 & 0.82 & 0.86 & 0.93 & 1.01 \\
\hline HST3-B & [16] & 5306 & 5995 & 6352 & 0.78 & 0.88 & 0.93 & 0.82 \\
\hline HST3-A & [16] & 5245 & 5929 & 6281 & 0.77 & 0.87 & 0.92 & 0.87 \\
\hline HST1-B & [16] & 4094 & 4334 & 4687 & 0.89 & 0.94 & 1.01 & 0.90 \\
\hline \multicolumn{5}{|c|}{ Mean } & 0.81 & 0.81 & 0.91 & 0.96 \\
\hline \multicolumn{5}{|c|}{ SD } & 0.076 & 0.129 & 0.110 & 0.092 \\
\hline \multicolumn{5}{|c|}{$\mathrm{COV}$} & 0.094 & 0.159 & 0.121 & 0.096 \\
\hline
\end{tabular}




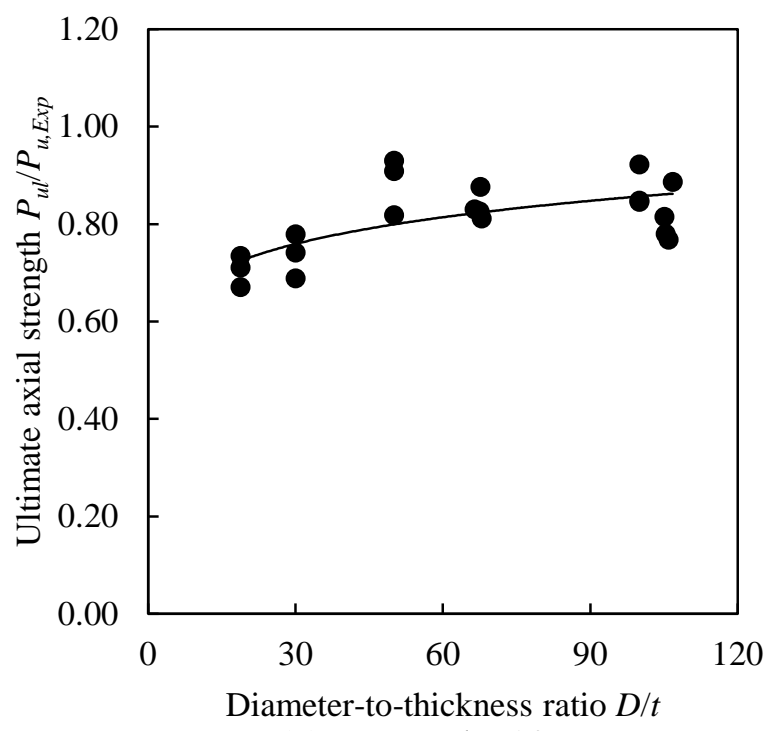

(a) Yu et al. [12]

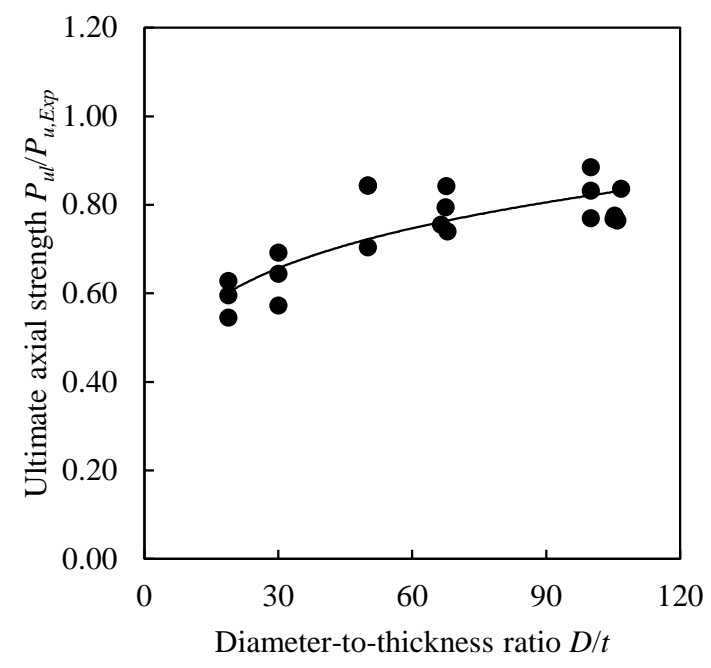

(b) Eurocode $4[13,17]$

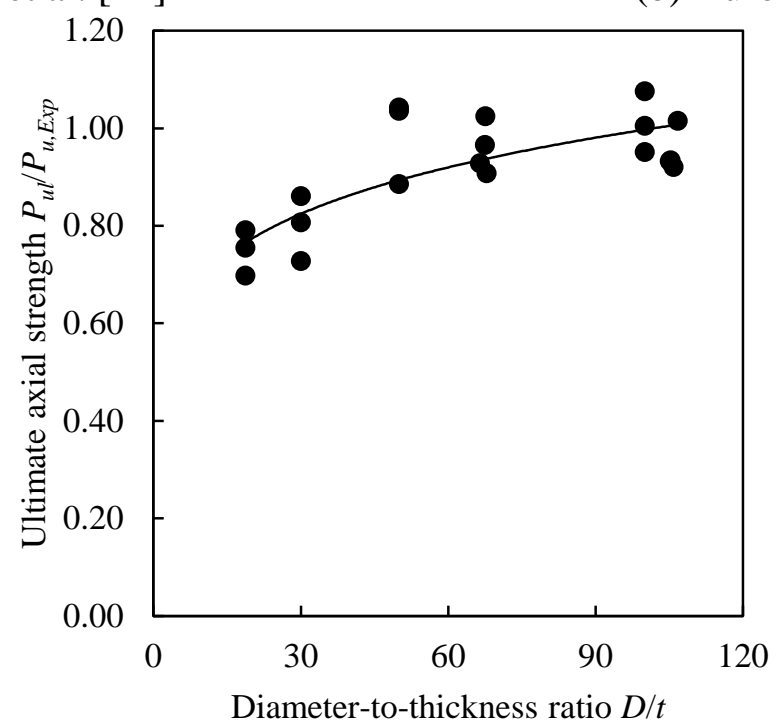

(c) Ding et al. [16]

Fig. 3: Comparison of design and ultimate axial loads for hexagonal CFST short columns with different $D / t$ ratios

\section{FE MODELLING STRATEGY AND VERIFICATION}

\subsection{Numerically modelled experiments}

The experimental results from two investigations conducted by Xu et al. [13] and Ding et al. [16] were used to assess the suitability of the FE modelling strategy adopted herein. These are the only investigations found in the literature on dual-axisymmetric and regular hexagonal CFST short columns, respectively, representing the mechanical behaviour of large-diameter 
columns [19]. The dimension and material strengths of the tests used in this section to develop the modelling strategy are given in Table 1.

The experimental investigation carried out by $\mathrm{Xu}$ et al. [13] consisted of 6 tests on hexagonal CFST short columns loaded axially. Outwards local buckling was observed as the main governing failure mode for thin-walled CFST columns. Ding et al. [16] also conducted a series of tests on hexagonal CFST columns with diameter-to-thickness ratio D/t varying from 66 to 107 . More detailed geometric and material strengths of the tested columns can be found in the literature $[13,16]$. The main geometric and material properties of the tested columns used in the present investigation are also reported in Table 1.

The material behaviour of the concrete core in a hexagonal CFST column is characterised by its geometric internal angle $(\theta)$ shown in Fig. 2. A hexagonal CFST column with $\theta=135^{\circ}$ has the same concrete behaviour as a rectangular CFST column, in which only the ductility of concrete core is increased by the concrete confinement [13]. The material model proposed by Liang [21] was utilized for simulating the concrete behaviour in hexagonal CFST columns with $\theta=135^{\circ}$. For $\theta=120^{\circ}$, the concrete confinement enhances both ductility and strength of hexagonal CFST columns [16].

\subsection{Modelling strategy}

The finite element (FE) software ABAQUS [18] was utilised to simulate the structural response of hexagonal CFST columns tested in [13] and [16]. Both geometric and material nonlinearities were accounted for in the FE model. The geometry of the hexagonal CFST columns was discretised using the 8-node general purpose brick element with reduced integration C3D8R available in Abaqus library. A mesh sensitivity analysis assuming same 
concrete core and steel tube mesh size was conducted to assess the effect of the mesh size on the ultimate strength. The results are given in Fig. 4 which shows that convergence is achieved if the elements are smaller than $100 \times 100 \mathrm{~mm}$. A mesh size of as $40 \times 40 \mathrm{~mm}$ was used for the concrete core while the steel tube mesh size was refined to $20 \times 20 \mathrm{~mm}$ to better capture local instabilities associated with thin-walled structures. This mesh size yields accurate results with reasonable computational time. A typical model including its meshing scheme and boundary conditions is depicted in Fig. 5. The FE modelling consisted of nonlinear load-deflection analysis step which was performed to trace the nonlinear responses of the models under the applied load. Surface-to-surface contact was used between the steel tube and the concrete core in the models with hard contact in the normal direction and penalty constrain algorithm with a coulomb friction coefficient of 0.3 for the tangential direction was simulated in both tangential and normal directions. The hard contact was defined for the contact in the normal direction [20]. The penalty constraint algorithm was utilized for simulating the contact in the tangential direction. The coulomb friction coefficient equal to 0.3 was used for interaction in tangential direction. Static analysis was used to trace the nonlinear load-deflection response of the models under the axial load applied.

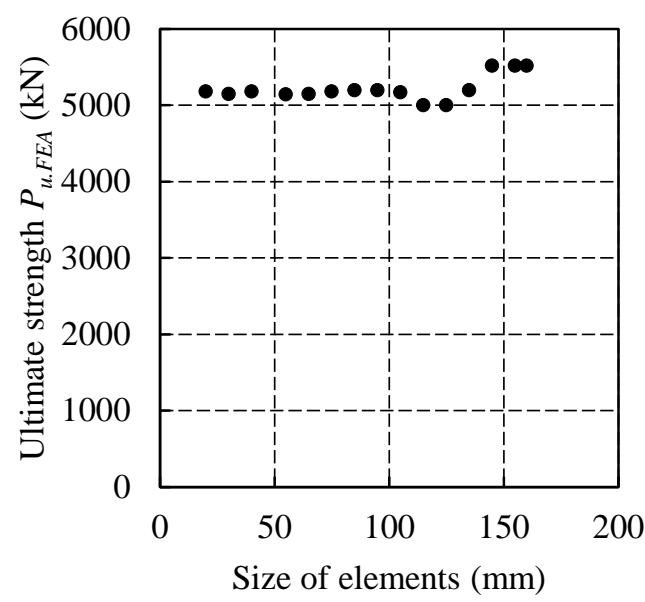

Fig. 4: Mesh sensitivity analysis 


\subsubsection{Material modelling of the steel tube}

Structural steels generally follow the same stress vs. strain response in tension and compression. The trilinear stress vs. strain curves for cold-formed and mild steels are illustrated in Fig. 6. It can be seen from the figure that the material response of steels reflects the yield and ultimate strengths and the corresponding strains. A linear-rounded-linear stress vs. strain response is used to simulate the material behaviour of cold-formed steels. A rounded part of the cold-formed steels shown in Fig. 6 is given by Liang [21]. In Fig. 6, $\varepsilon_{s}$ represents the steel strain, $\sigma_{s}$ denotes the stress at strain $\varepsilon_{s}, f_{s u}$ reflects the ultimate strengths of steel, $\varepsilon_{\text {su }}$ is the strain at $f_{s u}$ which is taken as 0.1 and $f_{y}$ is the yield strength of steel tube. The hardening strain $\left(\varepsilon_{t}\right)$ is taken as 0.005 .

$\sigma_{s}=f_{y}\left(\frac{\varepsilon_{s}-0.9 \varepsilon_{s y}}{\varepsilon_{s t}-0.9 \varepsilon_{s y}}\right)^{\frac{1}{45}} \quad\left(0.9 \varepsilon_{s y}<\varepsilon_{s} \leq \varepsilon_{s t}\right)$

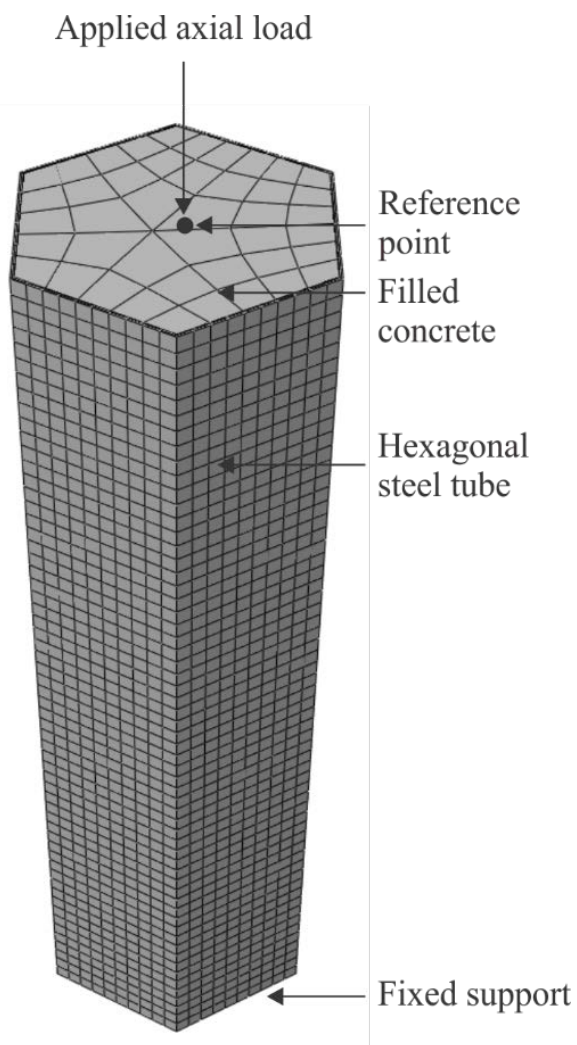

Fig. 5: Typical FE model and meshing scheme 


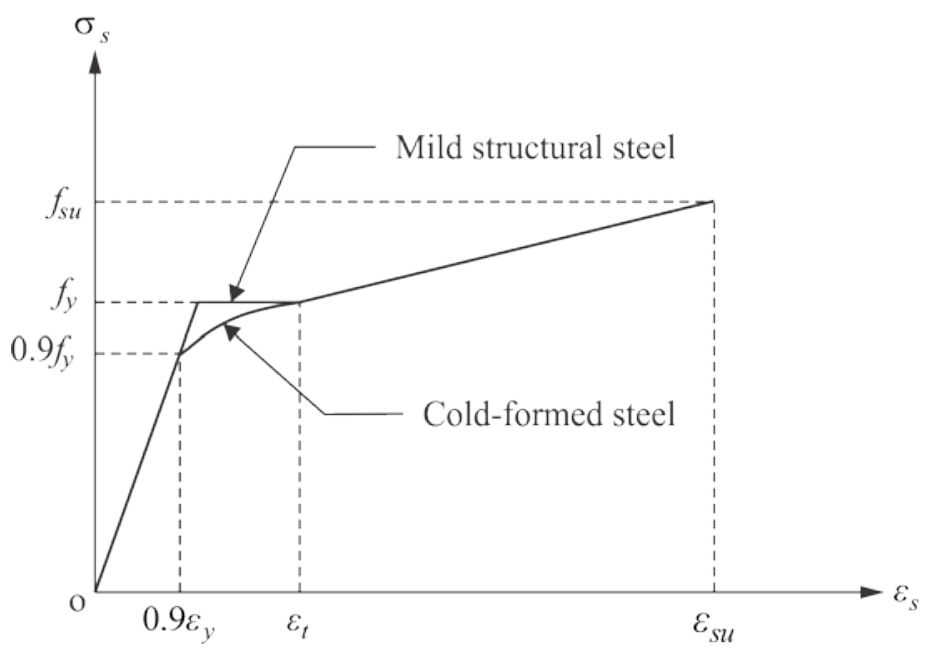

Fig. 6: Stress-strain response of structural steels

\subsubsection{Material modelling of confined concrete cores}

The confining pressure by the steel tube on the encased concrete in a hexagonal CFST column is passive. The concrete lateral expansion causes the hoop tension which induces compressive confining stress on the concrete core. The confining pressure increases as the axial strain increases. The passive confinement induced by the steel tube increases both strength and ductility of concrete core. The concrete in hexagonal CFST columns is exhibited triaxial stresses while the steel tube is subjected to biaxial stresses. The Drucker-Prager plasticity model is used for simulating the concrete material behaviour in compression after the linear response to define the yield surface and the flow potential parameters for materials subjected to triaxial compressive stresses. The yield stage of confined concrete is defined by two parameters (*DRUCKER PRAGER and *DRUCKER PRAGER HARDENING). The linear Drucker-Prager model is used with associated flow and isotropic rules [18], though more accurate modified Drucker-Prager model may be found by Yu, et al [22]. The stress versus strain curves for confined and unconfined concrete in regular hexagonal CFST columns is shown in Fig. 7. 


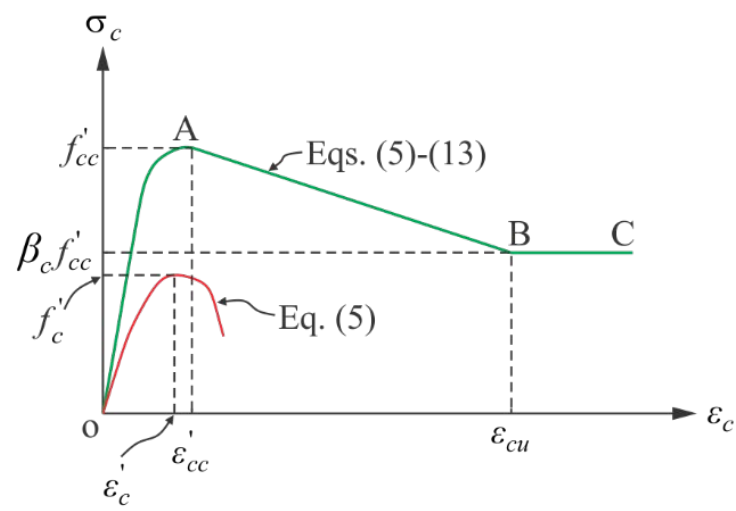

Fig. 7: Stress vs. strain curves for confined concrete of regular hexagonal CFST columns with $\theta=120^{\circ}$

The part OA of stress versus strain curve depicted in Fig. 7 is modelled using the formula proposed by Mander et al. [23] given in Eqs (5) and (6) below:

$$
\begin{aligned}
& \sigma_{c}=\frac{f_{c c}^{\prime} \lambda\left(\varepsilon_{c} / \varepsilon_{c c}^{\prime}\right)}{\lambda-1+\left(\varepsilon_{c} / \varepsilon_{c c}^{\prime}\right)^{\lambda}} \\
& \lambda=\frac{E_{c}}{E_{c}-\left(f_{c c}^{\prime} / \varepsilon_{c c}^{\prime}\right)}
\end{aligned}
$$

in which $\varepsilon_{c}$ illustrates the concrete strain, $\sigma_{c}$ represents the concrete stress at strain $\varepsilon_{c}, f_{c c}^{\prime}$ denotes the confined concrete strength resulting from to the Poisson's effect and the interaction with the confining steel in the lateral direction [7], $\varepsilon_{c c}^{\prime}$ is the strain at $f_{c c}^{\prime}$ and $E_{c}$ defines the elastic modulus of concrete as given in ACI 318-11 [24] and shown in Eqs. (7) and (8) below:

$$
\begin{aligned}
& E_{c}=3320 \sqrt{\gamma_{c} f_{c}^{\prime}}+6900 \quad(\mathrm{MPa}) \\
& \gamma_{c}=1.85 D_{c}^{-0.135} \quad\left(0.85 \leq \gamma_{c} \leq 1.0\right)
\end{aligned}
$$


where $\gamma_{c}$ represents the reduction factor for the effects of column size effect [21] and $D_{c}$ is taken as $(D-2 t)$ where $t$ is the thickness of the steel tube and $D$ is defined in Fig. 2. Liang and Fragomeni [25] modified the formula given by Mander et al. [23] using the reduction factor $\left(\gamma_{c}\right)$ as shown in Eqs (9) and (10) below:

$$
\begin{aligned}
& f_{c c}^{\prime}=\gamma_{c} f_{c}^{\prime}+4.1 f_{r p} \\
& \varepsilon_{c c}^{\prime}=\varepsilon_{c}^{\prime}\left[1+20.5\left(\frac{f_{r p}}{\gamma_{c} f_{c}^{\prime}}\right)\right]
\end{aligned}
$$

where $f_{c}^{\prime}$ is the concrete cylinder strength, $\varepsilon_{c}^{\prime}$ is the unconfined concrete strain at $f_{c}^{\prime}$ and $f_{r p}$ is the lateral confining pressure for which a model for circular CFST columns under axial loading utilising numerical models was proposed by Liang and Fragomeni [25]. It is worth pointing out that using the $f_{r p}$ in the the concrete constitutive model for three-dimensional applications is essential based on the fact that concrete behaviour is pressure dependent. In Abaqus programming [18], the developed pressure should be defined as it would not be developed with its own; refer for example to Refs. [25-30]. Following a similar approach to that presented in Ref. [25], an equation for the lateral confinement pressure of hexagonal columns is proposed herein. Firstly, the confined concrete strength $f_{c c}^{\prime}$ was calculated form the ultimate strengths of the experimental tests of Ding et al. [16] considering the superposition of the steel and concrete strengths $f_{s y} A_{s}+f_{c c}^{\prime} A_{c}$. Then, the experimental lateral confinement pressure $f_{r p, E x p}$ was determined by using Eq. (9). Several FE models with different confining pressures (around the $f_{r p, E x p}$ values) were subsequently generated for each specimen to get the best numerical load-deformation response relative to that obtain experimentally. The best numerical confinement pressures $\left(f_{r p}\right)$ is then determined. This 
numerical confinement pressures $\left(f_{r p}\right)$ relative to the steel's yield stress $f_{r p} / f_{s y}$ were plotted against $B+D / 2 t$ ratio, where $\mathrm{B}$ and $\mathrm{D}$ are defined in Fig.2, to perform a best fit regression analysis. The resulting linear law proposed to determine the confinement pressure of regular hexagonal CFST with $\theta=120^{\circ}$ is given in Eq. (11) and illustrated in Fig. 8.

$$
f_{r p}= \begin{cases}\left(0.0491703-0.0007943 \frac{B+D}{2 t}\right) f_{s y} & \text { for } 17 \leq \frac{B+D}{2 t}<63 \\ \left(0.0065311-0.0000044 \frac{B+D}{2 t}\right) f_{s y} & \text { for } 63 \leq \frac{B+D}{2 t} \leq 103\end{cases}
$$

The linear parts $\mathrm{AB}$ and $\mathrm{BC}$ of the material law shown in Fig. 7 are given by Eq. (12) below:

$$
\sigma_{c}= \begin{cases}\frac{\left(f_{c c}^{\prime}-\beta_{c} f_{c c}^{\prime}\right)\left(\varepsilon_{c u}-\varepsilon_{c}\right)}{\left(\varepsilon_{c u}-\varepsilon_{c c}^{\prime}\right)}+\beta_{c} f_{c c}^{\prime} & \text { for } \varepsilon_{c c}^{\prime}<\varepsilon_{c} \leq \varepsilon_{c u} \\ \beta_{c} f_{c c}^{\prime} & \text { for } \varepsilon_{c}>\varepsilon_{c u}\end{cases}
$$

in which $\varepsilon_{c u}$ is the concrete strain at Point B and the strain $\varepsilon_{c u}$ is taken as 0.02 as suggested by Liang and Fragomeni [25]. In Eq. (12), $\beta_{c}$ is the factor representing the confinement effects on strength and ductility in post-peak range. The factor $\beta_{c}$ is given by:

$$
\beta_{c}=0.8726-0.006 f_{c}^{\prime} \quad \text { for } 47 \leq \frac{B+D}{2 t} \leq 103
$$

Accordingly, it can be noticed that the softening behaviour of concrete in the post-yield stage (i.e. the parts $\mathrm{AB}$ and $\mathrm{BC}$ of the material law shown in Fig. 7) is determined by the parameter $\beta_{c}$ and concrete strain $\varepsilon_{c u}$, as defined above. 


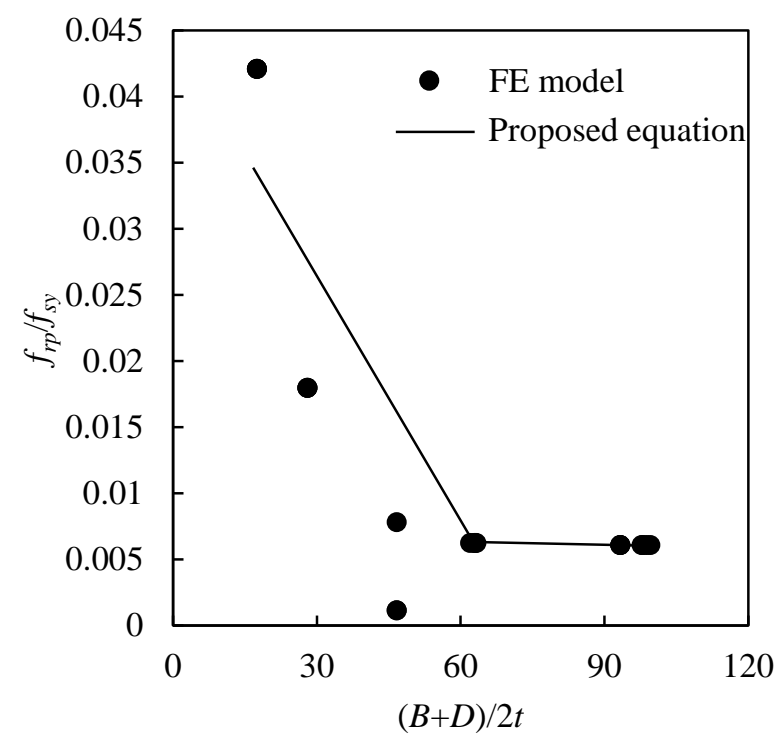

Fig. 8: Lateral confining pressure obtained from the finite element model for hexagonal

CFST columns.

\subsection{Validation of numerical model}

The numerical strengths $P_{u l, F E}$ achieved by the models are compared against test results $P_{u l, E x p}$ performed by by $\mathrm{Xu}$ et al. [13] and Ding et al. [16] in Table 3. Table 3 also includes the numerical to test ratio $P_{u l, F E} / P_{u l, E x p}$ and statistical parameters associated with this ratio including mean and coefficient of variation COV. The results show that the modelling strategy proposed herein for hexagonal CFST short tubes in compression is accurate with a mean value of 0.94 , which falls on the safe side and is close to the unity baseline, and low COV of 0.05 reflecting its reliability. It is believe that the numerical predictions are mostly falling on the safe side. The discrepancy between the numerical and experimental results is due to the uncertainty of the actual concrete strength and stiffness as the average concrete strength was used in the finite element model. The axial load-axial strain responses of the specimens tested by $\mathrm{Xu}$ et al. [13] and Ding et al. [16], where all specimens were tested twice, are given and compared against the predictions of the numerical model in Figs. 9 and 10. In these figures, it is worth paying attention to how different the response of two CFST of 
same geometric and material properties can be due to the heterogeneity of the concrete core as a material, and show that the response of the numerical model is realistic displaying axial load-axial strain responses fairly similar to that observed in the tests. However, Fig. 10 shows that the unconfined concrete model (Eq. 5) does not properly provide good agreement with the experimental results by using the current Drucker-Prager model. All test specimens failed by buckling of external steel tube as shown in Fig. 11 which compares the failure mode of specimen C2.5-1 and C2.5-2 with the deformed shape achieved in the FE model. As may be noticed, the validation focused on the load-axial strain responses and the deformed shapes, while the stress variations of concrete, which are often complex to capture when the concrete is non-uniformly confined over the current hexagonal section are not considered, owing to the following two main reasons, namely (1) the literature does not contain a measurement of such stresses to compare with and (2) provided that these stresses are available in literature, they would better be quantified by the concrete constitutive model modified by $\mathrm{Yu}$, et al [22].

Table 3: Ultimate strengths of axially loaded hexagonal CFST short columns

\begin{tabular}{|c|c|c|c|c|c|c|c|c|c|c|c|}
\hline Specimens & $\begin{array}{c}a_{o} \\
(\mathrm{~mm})\end{array}$ & $\begin{array}{c}t \\
(\mathrm{~mm})\end{array}$ & $\begin{array}{c}L \\
(\mathrm{~mm})\end{array}$ & $\begin{array}{c}\theta \\
\left({ }^{\circ}\right)\end{array}$ & $\begin{array}{c}f_{y} \\
(\mathrm{MPa})\end{array}$ & $\begin{array}{c}f_{u} \\
(\mathrm{MPa})\end{array}$ & $\begin{array}{c}E_{s} \\
(\mathrm{GPa})\end{array}$ & $\begin{array}{c}f_{c}^{\prime} \\
(\mathrm{MPa})\end{array}$ & $\begin{array}{c}P_{u l, E x p} \\
(\mathrm{kN})\end{array}$ & $\begin{array}{c}P_{u l, \text { FEA }} \\
(\mathrm{kN})\end{array}$ & $\frac{P_{u l, \text { FEA }}}{P_{u l, \text { Exp }}}$ \\
\hline C4-1 & 100 & 3.95 & 600 & 135 & 279 & 427 & 204 & 53.13 & 1865 & 1683 & 0.90 \\
\hline C4-2 & 100 & 3.95 & 600 & 135 & 279 & 427 & 204 & 53.13 & 1845 & 1683 & 0.91 \\
\hline C2.5-1 & 100 & 2.46 & 600 & 135 & 313 & 438 & 204 & 53.13 & 1598 & 1511 & 0.95 \\
\hline C2.5-2 & 100 & 2.46 & 600 & 135 & 313 & 438 & 204 & 53.13 & 1492 & 1511 & 1.01 \\
\hline C6-1 & 100 & 5.93 & 600 & 135 & 302 & 429 & 198 & 53.13 & 2062 & 2106 & 1.02 \\
\hline C6-2 & 100 & 5.93 & 600 & 135 & 302 & 429 & 198 & 53.13 & 2195 & 2106 & 0.96 \\
\hline HST1-A & 196 & 3.73 & 1200 & 120 & 311 & 460 & 209 & 32.24 & 4947 & 4522 & 0.91 \\
\hline HST1-B & 198 & 3.71 & 1200 & 120 & 311 & 460 & 209 & 32.24 & 4618 & 4522 & 0.98 \\
\hline HST2-A & 196 & 5.78 & 1200 & 120 & 321 & 480 & 202 & 32.24 & 6001 & 5379 & 0.90 \\
\hline HST2-B & 198 & 5.96 & 1200 & 120 & 321 & 480 & 202 & 32.24 & 6041 & 5379 & 0.89 \\
\hline HST3-A & 197 & 3.72 & 1200 & 120 & 311 & 460 & 209 & 48.98 & 6827 & 5940 & 0.87 \\
\hline HST3-B & 197 & 3.76 & 1200 & 120 & 311 & 460 & 209 & 48.98 & 6803 & 5940 & 0.87 \\
\hline HST4-A & 199 & 5.89 & 1200 & 120 & 321 & 480 & 202 & 48.98 & 7079 & 6924 & 0.98 \\
\hline HST4-B & 196 & 5.81 & 1200 & 120 & 321 & 480 & 202 & 48.98 & 7289 & 6924 & 0.95 \\
\hline & \multicolumn{9}{|c|}{ Mean } \\
\hline
\end{tabular}




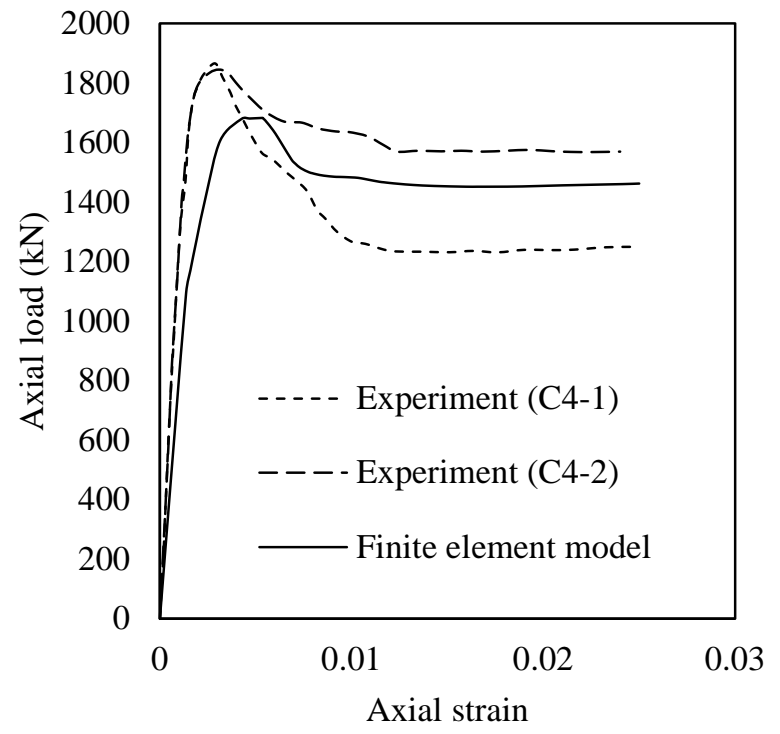

(a) Specimens C4-1 and C4-2

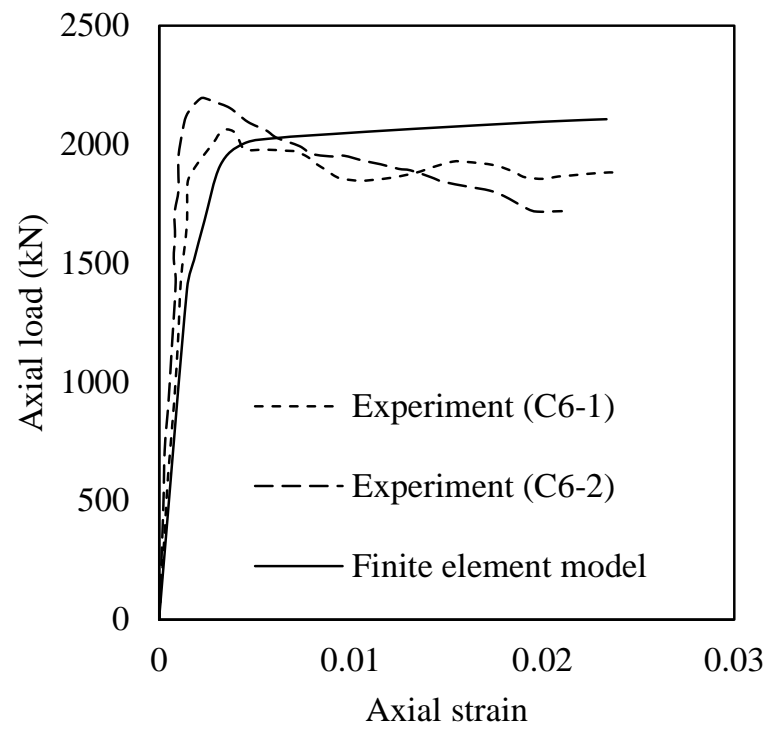

(c) Specimens C6-1 and C6-2

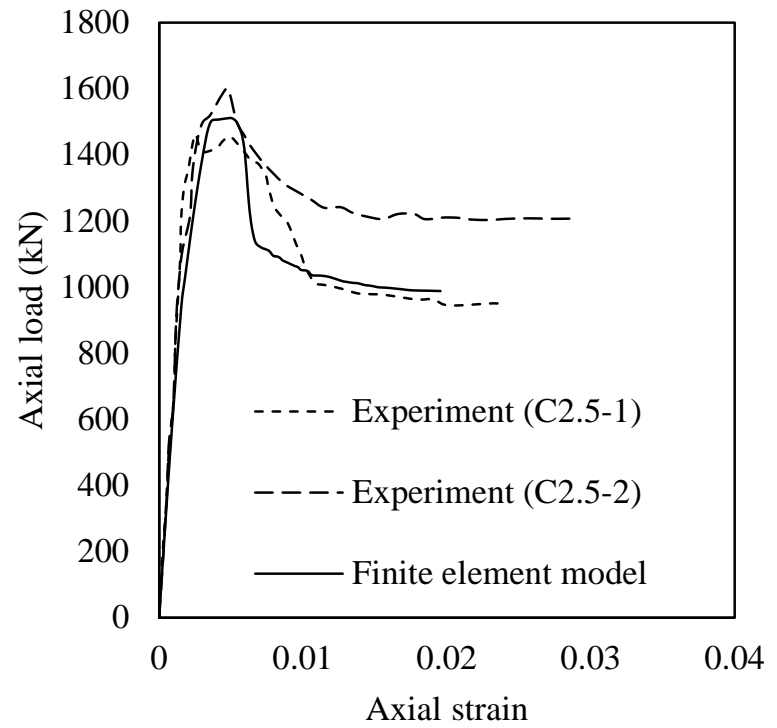

(b) Specimens C2.5-1 and C2.5-2 

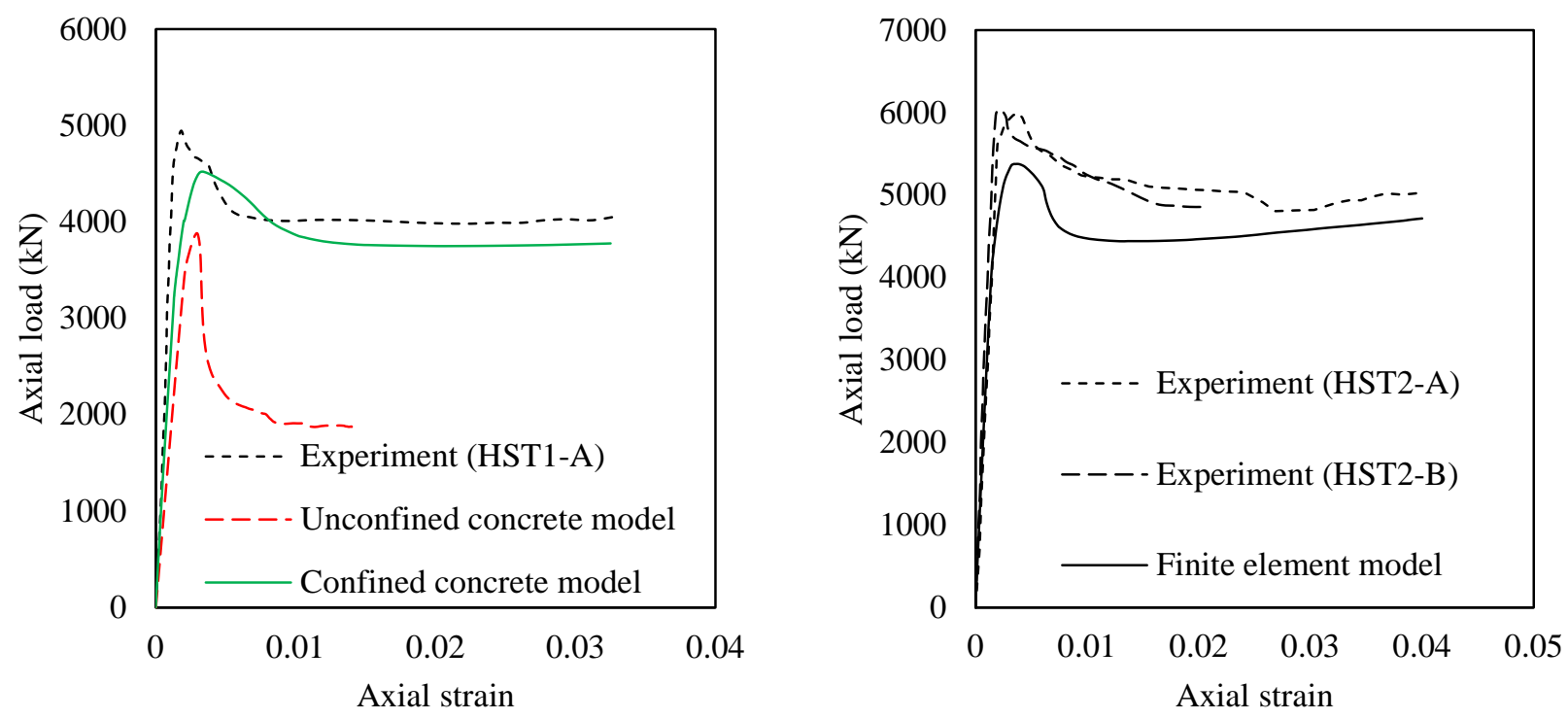

(a) Specimens HST1-A and HST1-B

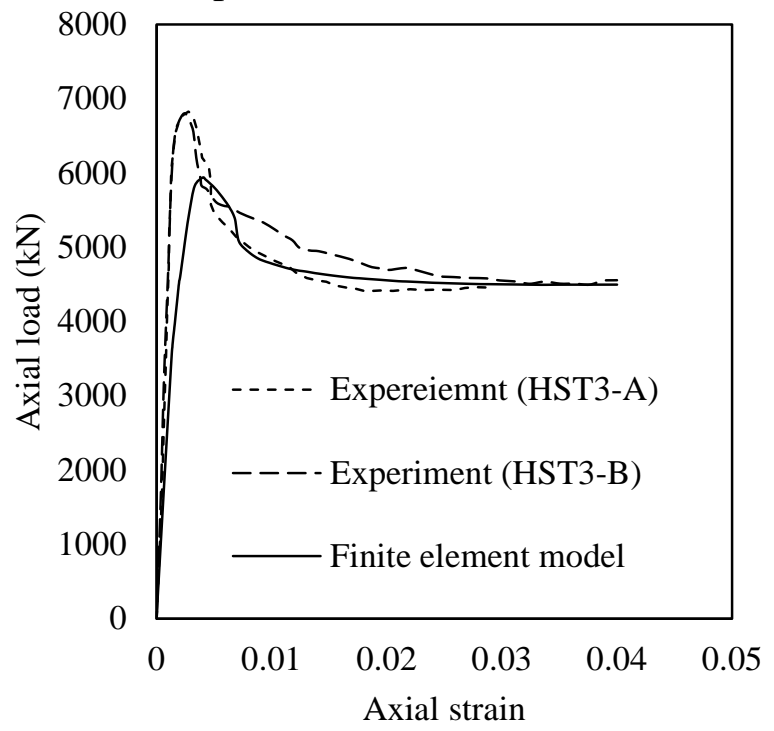

(b) Specimens HST2-A and HST2-B

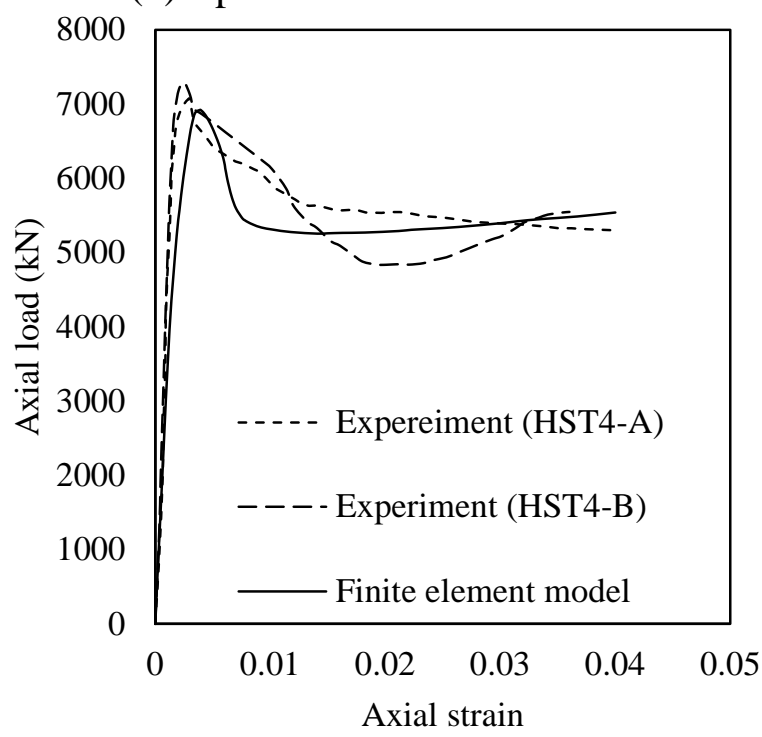

(c) Specimens HST3-A and HST3-B

(d) Specimens HST4-A and HST4-B

Fig. 10: Comparison of axial load-strain responses for test data reported by Ding et al. [16] 


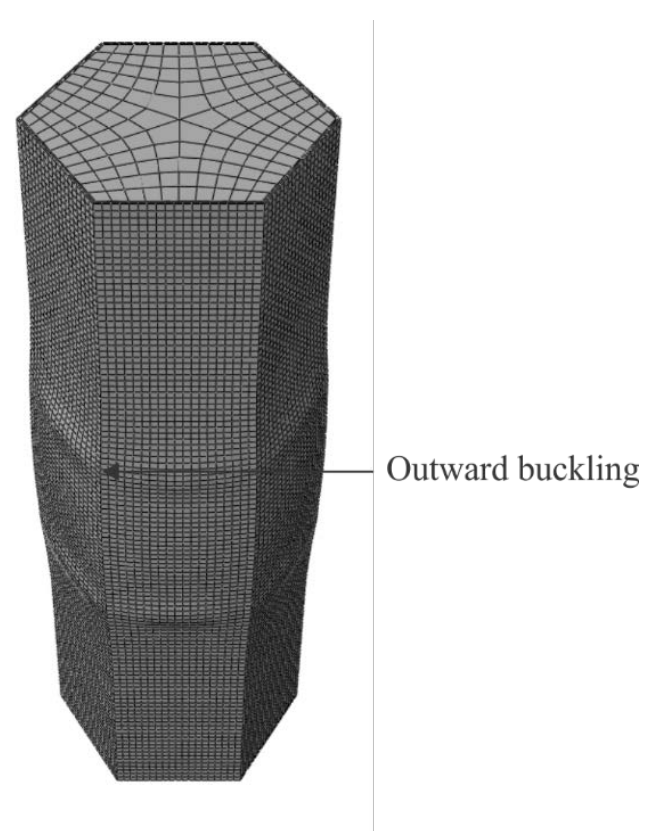

Fig. 11: Deformed shape for Specimens C2.5-1 and C2.5-2.

\section{PARAMETRic ANALYSES}

Having demonstrated that the finite element model can effectively simulate the strength and behaviour in terms of the ultimate load, load-deformation response and deformed shape, a further parametric analysis is conducted in this section to explore what the behaviour of hexagonal CFST short columns in compression would be upon varying various material and geometrical parameters. The generated models aim at expanding the existing database so that a more efficient and accurate design method can be proposed. Material wise, this parametric analysis covers three steel materials of yield strength $\left(f_{y}\right)$ of 250, 350 and 450MPa, and three different concrete compressive strengths $f_{c}^{\prime}$ of 40, 65 and 80MPa. Regarding variations in geometry, column diameters $(D)$ of 400, 500 and 600mm and thicknesses $(t)$ ranging from 4 to $16 \mathrm{~mm}$ resulting in an array of $D / t$ ratios between 28.57 and 100 were considered. A total number of 162 numerical models including 18 basic geometries were generated. 
It should be noted that an upper limit of 100 for the $D / t$ ratio was intentionally chosen to ensure that the $(D+B) / 2 t$ ratios are in the validity range of the lateral confining pressure ( $f_{r p}$ ) on the concrete core of the current hexagonal CFST short columns suggested in Eq. (11). To make the results easy to understand, the models generated were divided into three groups (G1 and G2 and G3) according to their concrete strength value $f_{c}^{\prime}$ and then subdivided into three groups (i.e. G1-1, G1-2 and G1-3) based on their steel yield strength $f_{y}$. The results are presented in Tables 4-6 for G1, G2 and G3 with concrete strength values $f_{c}^{\prime}$ of 40, 65 and 80MPa, respectively.

In assessing the structural performance of CFST columns, it is important to quantify the concrete contribution of the total strength of the column which is defined by the concrete contribution ratio (CCR). An expression for the CCR proposed by Liang et al. [26] given in Eq. (14) is used. The inputs required to determine the CCR are the ultimate strength of the CFST column $P_{u l, F E}$ as denoted above and the ultimate strength of the steel tube alone $P_{u l, F E, S T}$. Therefore, $54 \mathrm{FE}$ models for hexagonal tubes were additionally generated to get the $P_{u l, F E, S T}$ values, and in turn they were used to compute the CCRs as shown in Table 7.

$$
C C R=\frac{P_{u l, F E}-P_{u l, F E, S T}}{P_{u l, F E}}
$$


Table 4: Details and ultimate strengths of the FE models of hexagonal CFST short columns with $f_{c}^{\prime}=40 \mathrm{MPa}-\mathrm{G} 1$

\begin{tabular}{|c|c|c|c|c|c|c|c|c|c|}
\hline \multicolumn{4}{|c|}{ Cross-sectional dimensions } & \multicolumn{2}{|c|}{$\begin{array}{c}\text { G1-1: } \\
f_{y}=250 \mathrm{MPa} \\
\end{array}$} & \multicolumn{2}{|c|}{$\begin{array}{c}\mathrm{G} 1-2: \\
f_{y}=350 \mathrm{MPa}\end{array}$} & \multicolumn{2}{|c|}{$\begin{array}{c}\text { G1-3: } \\
f_{y}=450 \mathrm{MPa}\end{array}$} \\
\hline$\underset{(\mathrm{mm})}{D}$ & $\underset{(\mathrm{mm})}{B}$ & $\begin{array}{c}t \\
(\mathrm{~mm})\end{array}$ & $\frac{D}{t}$ & No. & $\begin{array}{c}P_{u l . F E} \\
(\mathrm{kN})\end{array}$ & No. & $\begin{array}{c}P_{u l . F E} \\
(\mathrm{kN})\end{array}$ & No. & $\begin{array}{c}P_{\text {ul.FE }} \\
(\mathrm{kN})\end{array}$ \\
\hline \multirow{6}{*}{400} & \multirow{6}{*}{346} & 4.00 & 100.00 & C1 & 5176 & C19 & 5816 & C37 & 6479 \\
\hline & & 6.00 & 66.67 & C2 & 5681 & C20 & 6538 & C38 & 7408 \\
\hline & & 8.00 & 50.00 & C3 & 6731 & C21 & 8029 & C39 & 9324 \\
\hline & & 10.00 & 40.00 & C4 & 7895 & C22 & 9687 & $\mathrm{C} 40$ & 11513 \\
\hline & & 12.00 & 33.33 & C5 & 8791 & C23 & 10937 & C41 & 13213 \\
\hline & & 14.00 & 28.57 & C6 & 9548 & C24 & 12052 & C42 & 14602 \\
\hline \multirow{6}{*}{500} & \multirow{6}{*}{433} & 5.00 & 100.00 & C7 & 8089 & C25 & 9086 & C43 & 10087 \\
\hline & & 6.00 & 83.33 & C8 & 8369 & C26 & 9536 & C44 & 10684 \\
\hline & & 8.00 & 62.50 & C9 & 8505 & C27 & 9683 & C45 & 10908 \\
\hline & & 10.00 & 50.00 & C10 & 10511 & C28 & 12538 & C46 & 14618 \\
\hline & & 12.00 & 41.67 & C11 & 11732 & C29 & 14682 & C47 & 17365 \\
\hline & & 14.00 & 35.71 & C12 & 13202 & C30 & 16325 & C48 & 19647 \\
\hline \multirow{6}{*}{600} & \multirow{6}{*}{520} & 6.00 & 100.00 & C13 & 11651 & C31 & 13084 & C49 & 14557 \\
\hline & & 8.00 & 75.00 & C14 & 12355 & C32 & 14184 & C50 & 15961 \\
\hline & & 10.00 & 60.00 & C15 & 12802 & C33 & 14730 & C51 & 16744 \\
\hline & & 12.00 & 50.00 & C16 & 15141 & C34 & 18063 & C52 & 21052 \\
\hline & & 14.00 & 42.86 & C17 & 16925 & C35 & 20683 & C53 & 24403 \\
\hline & & 16.00 & 37.50 & C18 & 18459 & C36 & 22860 & C54 & 27252 \\
\hline
\end{tabular}

Table 5: Details and ultimate strengths of the FE models of hexagonal CFST short columns with $f_{c}^{\prime}=65 \mathrm{MPa}-\mathrm{G} 2$

\begin{tabular}{|c|c|c|c|c|c|c|c|c|c|}
\hline \multicolumn{4}{|c|}{ Cross-sectional dimensions } & \multicolumn{2}{|c|}{$\begin{array}{c}\text { G2-1: } \\
f_{y}=250 \mathrm{MPa}\end{array}$} & \multicolumn{2}{|c|}{$\begin{array}{c}\mathrm{G} 2-2: \\
f_{y}=350 \mathrm{MPa}\end{array}$} & \multicolumn{2}{|c|}{$\begin{array}{c}\mathrm{G} 2-3: \\
f_{y}=450 \mathrm{MPa}\end{array}$} \\
\hline$\underset{(\mathrm{mm})}{D}$ & $\underset{(\mathrm{mm})}{B}$ & $\begin{array}{c}t \\
(\mathrm{~mm})\end{array}$ & $\frac{D}{t}$ & No. & $\begin{array}{c}P_{\text {ul.FE }} \\
(\mathrm{kN})\end{array}$ & No. & $\begin{array}{c}P_{u l . F E} \\
(\mathrm{kN})\end{array}$ & No. & $\begin{array}{c}P_{\text {ul.FE }} \\
(\mathrm{kN})\end{array}$ \\
\hline \multirow{6}{*}{400} & \multirow{6}{*}{346} & 4.00 & 100.00 & C55 & 7222 & C73 & 7951 & C91 & 8610 \\
\hline & & 6.00 & 66.67 & C56 & 7691 & C74 & 8618 & C92 & 9486 \\
\hline & & 8.00 & 50.00 & C57 & 8726 & C75 & 10070 & C93 & 11341 \\
\hline & & 10.00 & 40.00 & C58 & 9857 & C76 & 11689 & C94 & 13508 \\
\hline & & 12.00 & 33.33 & C59 & 10711 & C77 & 12903 & C95 & 15163 \\
\hline & & 14.00 & 28.57 & C60 & 11372 & C78 & 13949 & C96 & 16521 \\
\hline \multirow{6}{*}{500} & \multirow{6}{*}{433} & 5.00 & 100.00 & C61 & 11305 & C79 & 12427 & C97 & 13455 \\
\hline & & 6.00 & 83.33 & C62 & 11595 & $\mathrm{C} 80$ & 12847 & C98 & 14006 \\
\hline & & 8.00 & 62.50 & C63 & 11656 & C81 & 12918 & C99 & 14118 \\
\hline & & 10.00 & 50.00 & C64 & 13640 & C82 & 15725 & C100 & 17802 \\
\hline & & 12.00 & 41.67 & C65 & 15066 & C83 & 17820 & C101 & 20514 \\
\hline & & 14.00 & 35.71 & C66 & 16239 & C84 & 19454 & C102 & 22736 \\
\hline \multirow{6}{*}{600} & \multirow{6}{*}{520} & 6.00 & 100.00 & C67 & 16286 & C85 & 17893 & C103 & 19376 \\
\hline & & 8.00 & 75.00 & C68 & 16980 & C86 & 18889 & C104 & 20662 \\
\hline & & 10.00 & 60.00 & C69 & 17294 & C87 & 19388 & C105 & 21344 \\
\hline & & 12.00 & 50.00 & C70 & 19634 & C88 & 22658 & C106 & 25632 \\
\hline & & 14.00 & 42.86 & C71 & 21422 & C89 & 25158 & C107 & 28934 \\
\hline & & 16.00 & 37.50 & C72 & 22884 & C90 & 27236 & C108 & 31745 \\
\hline
\end{tabular}


Table 6: Details and ultimate strengths of the FE models of hexagonal CFST short columns with $f_{c}^{\prime}=80 \mathrm{MPa}-\mathrm{G} 3$

\begin{tabular}{|c|c|c|c|c|c|c|c|c|c|}
\hline \multicolumn{4}{|c|}{ Cross-sectional dimensions } & \multicolumn{2}{|c|}{$\begin{array}{c}\text { G3-1: } \\
f_{y}=250 \mathrm{MPa} \\
\end{array}$} & \multicolumn{2}{|c|}{$\begin{array}{c}\text { G3-2: } \\
f_{y}=350 \mathrm{MPa}\end{array}$} & \multicolumn{2}{|c|}{$\begin{array}{c}\text { G3-3: } \\
f_{y}=450 \mathrm{MPa}\end{array}$} \\
\hline$\underset{(\mathrm{mm})}{D}$ & $\underset{(\mathrm{mm})}{B}$ & $\begin{array}{c}t \\
(\mathrm{~mm})\end{array}$ & $\frac{D}{t}$ & No. & $\begin{array}{c}P_{\text {ul.FE }} \\
(\mathrm{kN})\end{array}$ & No. & $\begin{array}{c}P_{u l . F E} \\
(\mathrm{kN})\end{array}$ & No. & $\begin{array}{c}P_{u l . F E} \\
(\mathrm{kN})\end{array}$ \\
\hline \multirow{6}{*}{400} & \multirow{6}{*}{346} & 4.00 & 100.00 & C109 & 8511 & C127 & 9178 & C145 & 10517 \\
\hline & & 6.00 & 66.67 & C110 & 8942 & C128 & 9673 & C146 & 11732 \\
\hline & & 8.00 & 50.00 & C111 & 9909 & C129 & 11251 & C147 & 12605 \\
\hline & & 10.00 & 40.00 & C112 & 11023 & C130 & 12869 & C148 & 14728 \\
\hline & & 12.00 & 33.33 & C113 & 11852 & C131 & 14091 & C149 & 16288 \\
\hline & & 14.00 & 28.57 & C114 & 12524 & C132 & 15086 & C150 & 17666 \\
\hline \multirow{6}{*}{500} & \multirow{6}{*}{433} & 5.00 & 100.00 & C115 & 13295 & C133 & 14344 & C151 & 15435 \\
\hline & & 6.00 & 83.33 & C116 & 13569 & C134 & 14748 & C152 & 16010 \\
\hline & & 8.00 & 62.50 & C117 & 13551 & C135 & 14841 & C153 & 16072 \\
\hline & & 10.00 & 50.00 & C118 & 15489 & C136 & 17592 & C154 & 19697 \\
\hline & & 12.00 & 41.67 & C119 & 16920 & C137 & 19689 & C155 & 22438 \\
\hline & & 14.00 & 35.71 & C120 & 18045 & C138 & 21314 & C156 & 24455 \\
\hline \multirow{6}{*}{600} & \multirow{6}{*}{520} & 6.00 & 100.00 & C121 & 19197 & C139 & 20650 & C157 & 22264 \\
\hline & & 8.00 & 75.00 & C122 & 19834 & C140 & 21708 & C158 & 23538 \\
\hline & & 10.00 & 60.00 & C123 & 20052 & C141 & 22166 & C159 & 24040 \\
\hline & & 12.00 & 50.00 & C124 & 22312 & C142 & 25334 & C160 & 28407 \\
\hline & & 14.00 & 42.86 & C125 & 24096 & C143 & 27917 & C161 & 31714 \\
\hline & & 16.00 & 37.50 & C126 & 25352 & C144 & 29923 & C162 & 34450 \\
\hline
\end{tabular}

Table 7: Details and ultimate strengths of the FE models of the hexagonal tubes

\begin{tabular}{|c|c|c|c|c|c|c|c|c|c|}
\hline \multicolumn{4}{|c|}{ Cross-sectional dimensions } & \multicolumn{2}{|c|}{$f_{y}=250 \mathrm{MPa}$} & \multicolumn{2}{|c|}{$f_{y}=350 \mathrm{MPa}$} & \multicolumn{2}{|c|}{$f_{y}=450 \mathrm{MPa}$} \\
\hline $\begin{array}{c}D \\
(\mathrm{~mm})\end{array}$ & $\begin{array}{c}B \\
(\mathrm{~mm})\end{array}$ & $\begin{array}{c}t \\
(\mathrm{~mm})\end{array}$ & $\frac{D}{t}$ & No. & $\begin{array}{c}P_{u l . F E, S T} \\
(\mathrm{kN})\end{array}$ & No. & $\begin{array}{c}P_{u l . F E, S T} \\
(\mathrm{kN})\end{array}$ & No. & $\begin{array}{c}P_{u l . F E, S T} \\
(\mathrm{kN})\end{array}$ \\
\hline \multirow{6}{*}{400} & \multirow{6}{*}{346} & 4.00 & 100.00 & C1 & 1344 & C19 & 1686 & C37 & 2146 \\
\hline & & 6.00 & 66.67 & C2 & 1851 & C20 & 2487 & C38 & 3184 \\
\hline & & 8.00 & 50.00 & C3 & 2402 & C21 & 3293 & C39 & 4221 \\
\hline & & 10.00 & 40.00 & C4 & 3026 & C22 & 4104 & C40 & 5258 \\
\hline & & 12.00 & 33.33 & $\mathrm{C} 5$ & 3724 & C23 & 4912 & C41 & 6289 \\
\hline & & 14.00 & 28.57 & C6 & 4477 & C24 & 5722 & C42 & 7320 \\
\hline \multirow{6}{*}{500} & \multirow{6}{*}{433} & 5.00 & 100.00 & C7 & 1871 & C25 & 2591 & C43 & 3315 \\
\hline & & 6.00 & $\begin{array}{l}83.33 \\
\end{array}$ & C8 & 2219 & C26 & 3091 & C44 & 3939 \\
\hline & & 8.00 & 62.50 & C9 & 2946 & C27 & 4105 & C45 & 5236 \\
\hline & & 10.00 & 50.00 & C10 & 3666 & C28 & 5119 & C46 & 6573 \\
\hline & & 12.00 & 41.67 & C11 & 4378 & C29 & 6141 & C47 & 7875 \\
\hline & & 14.00 & 35.71 & C12 & 5084 & C30 & 7149 & C48 & 9172 \\
\hline \multirow{6}{*}{600} & \multirow{6}{*}{520} & 6.00 & 100.00 & $\mathrm{C} 13$ & 2669 & C31 & 3652 & C49 & 4458 \\
\hline & & 8.00 & 75.00 & C14 & 3545 & C32 & 4889 & C50 & 6138 \\
\hline & & 10.00 & 60.00 & C15 & 4415 & C33 & 6138 & C51 & 7853 \\
\hline & & 12.00 & 50.00 & C16 & 5278 & C34 & 7355 & C52 & 9443 \\
\hline & & 14.00 & 42.86 & C17 & 6135 & C35 & 8587 & C53 & 10998 \\
\hline & & 16.00 & 37.50 & C18 & 7906 & C36 & 9806 & C54 & 12581 \\
\hline
\end{tabular}




\section{FUNDAMENTAL BEHAVIOUR OF HEXAGONAL CFST SHORT}

\section{COLUMNS}

This section gives a throughout presentation and analysis of the models generated based on parametric studies undertaken above to investigate the behaviour of hexagonal CFST short columns axially loaded. Firstly, the benefits of hexagonal CFST as a composite structural column against hexagonal steel tubes with no concrete core is given and then this sections extends to analyse the impact of the diameter-to-thickness $(D / t)$ ratios, the concrete compressive strengths $\left(f_{c}^{\prime}\right)$ and finally the steel yield strength $f_{y}$.

\subsection{Effects of in-fill concrete}

A strength index (SI) is considered herein to quantify the benefits of filling steel tubes with concrete to compositely form CFST columns. This is directly taken as the ratio dividing the strength of the CFST column $\left(P_{u l, F E}\right)$ by that corresponding to the hexagonal steel tube ( $\left.P_{u l, F E, S T}\right)$. Table 8 shows the values of these indices for the columns of sub-group G1-1 which are formed by using the minimum considered steel material grade and concrete compressive strength of 250 and $40 \mathrm{MPa}$, respectively. From this table, it is observed a considerable increase in the strength results from using the CFST column instead of the bare steel tube. This is obvious from the high values of the SI that range from 2.13 to 4.37 for these models. A trend that could clearly be noticed is that the SI increases with the decrease of the $D / t$ ratio, indicating that the CFST column becomes more effective with more slender crosssections. It is worth pointing out that the effect of increasing the steel material grade and the concrete compressive strength is evaluated in next sub-sections. 


\subsection{Effects of $D / t$ ratio}

Herein, the effects of the diameter-to-thickness $(D / t)$ ratios on the ultimate strengths $\left(P_{u l, F E}\right)$ and the load-strain curves of the axially-loaded hexagonal CFST short columns are presented. The external diameters of the steel sections $(D)$ of $600 \mathrm{~mm}$ were kept constant. The axial load versus strain relationships of columns C50-C54 with $f_{c}^{\prime}=40 \mathrm{MPa}$, columns C104-C108 with $f_{c}^{\prime}=65 \mathrm{MPa}$ and columns C158-C162 with $f_{c}^{\prime}=80 \mathrm{MPa}$ are illustrated in Fig. 11, as sample results. The strain considered is the average axial strain computed as the end shortening of the column over its length. Overall, the axial load-strain curves show a typical response with ascending and descending branches for the columns of different $D / t$ ratios. Obviously, it can be seen that increasing the $D / t$ ratio irrespective of the $f_{c}^{\prime}$ value, for the hexagonal CFST short columns of different $f_{c}^{\prime}$ values, significantly reduces the ultimate axial strength while stiffness decreases slightly. However, it can be seen that a considerable residual strength remains after failure.

Table 8: Strength Index calculated for G1-1

\begin{tabular}{|c|c|c|c|c|}
\hline \multicolumn{3}{|c|}{$\begin{array}{c}\text { Cross-sectional } \\
\text { dimensions }\end{array}$} & \multicolumn{2}{c|}{$\begin{array}{c}\text { G1-1: } \\
f_{y}=250 \mathrm{MPa}\end{array}$} \\
\hline $\begin{array}{c}D \\
(\mathrm{~mm})\end{array}$ & $\begin{array}{c}t \\
(\mathrm{~mm})\end{array}$ & $\frac{D}{t}$ & No. & SI \\
\hline \multirow{5}{*}{400} & 4.00 & 100.00 & $\mathrm{C} 1$ & 3.85 \\
\cline { 2 - 5 } & 6.00 & 66.67 & $\mathrm{C} 2$ & 3.07 \\
\cline { 2 - 5 } & 8.00 & 50.00 & $\mathrm{C} 3$ & 2.80 \\
\cline { 2 - 5 } & 10.00 & 40.00 & $\mathrm{C} 4$ & 2.61 \\
\cline { 2 - 5 } & 12.00 & 33.33 & $\mathrm{C} 5$ & 2.36 \\
\cline { 2 - 5 } & 14.00 & 28.57 & $\mathrm{C} 6$ & 2.13 \\
\hline \multirow{5}{*}{500} & 5.00 & 100.00 & $\mathrm{C} 7$ & 4.32 \\
\cline { 2 - 5 } & 6.00 & 83.33 & $\mathrm{C} 8$ & 3.77 \\
\cline { 2 - 5 } & 8.00 & 62.50 & $\mathrm{C} 9$ & 2.89 \\
\cline { 2 - 5 } & 10.00 & 50.00 & $\mathrm{C} 10$ & 2.87 \\
\cline { 2 - 5 } & 12.00 & 41.67 & $\mathrm{C} 11$ & 2.68 \\
\cline { 2 - 5 } & 14.00 & 35.71 & $\mathrm{C} 12$ & 2.60 \\
\hline \multirow{5}{*}{600} & 6.00 & 100.00 & $\mathrm{C} 13$ & 4.37 \\
\cline { 2 - 5 } & 8.00 & 75.00 & $\mathrm{C} 14$ & 3.49 \\
\cline { 2 - 5 } & 10.00 & 60.00 & $\mathrm{C} 15$ & 2.90 \\
\cline { 2 - 5 } & 12.00 & 50.00 & $\mathrm{C} 16$ & 2.87 \\
\cline { 2 - 5 } & 14.00 & 42.86 & $\mathrm{C} 17$ & 2.76 \\
\hline
\end{tabular}




\begin{tabular}{|c|c|c|c|c|}
\hline \multicolumn{3}{|c|}{$\begin{array}{c}\text { Cross-sectional } \\
\text { dimensions }\end{array}$} & \multicolumn{2}{|c|}{$\begin{array}{c}\text { G1-1: } \\
f_{y}=250 \mathrm{MPa}\end{array}$} \\
\hline $\begin{array}{c}D \\
(\mathrm{~mm})\end{array}$ & $\begin{array}{c}t \\
(\mathrm{~mm})\end{array}$ & $\frac{D}{t}$ & No. & SI \\
\hline & 16.00 & 37.50 & C18 & 2.33 \\
\hline \multicolumn{4}{|c|}{ Min } & 2.13 \\
\hline & & & & 4.37 \\
\hline
\end{tabular}

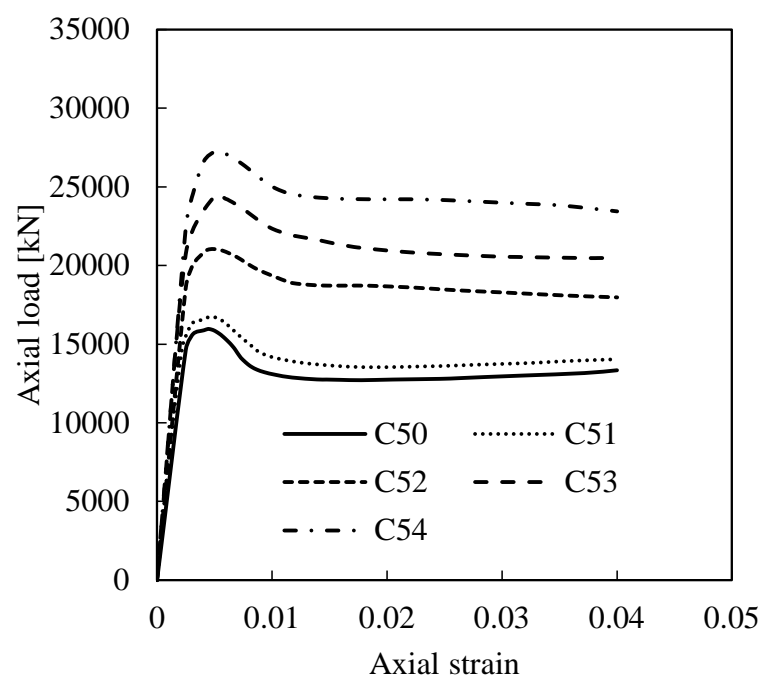

(a) $\mathrm{C} 50-\mathrm{C} 54$

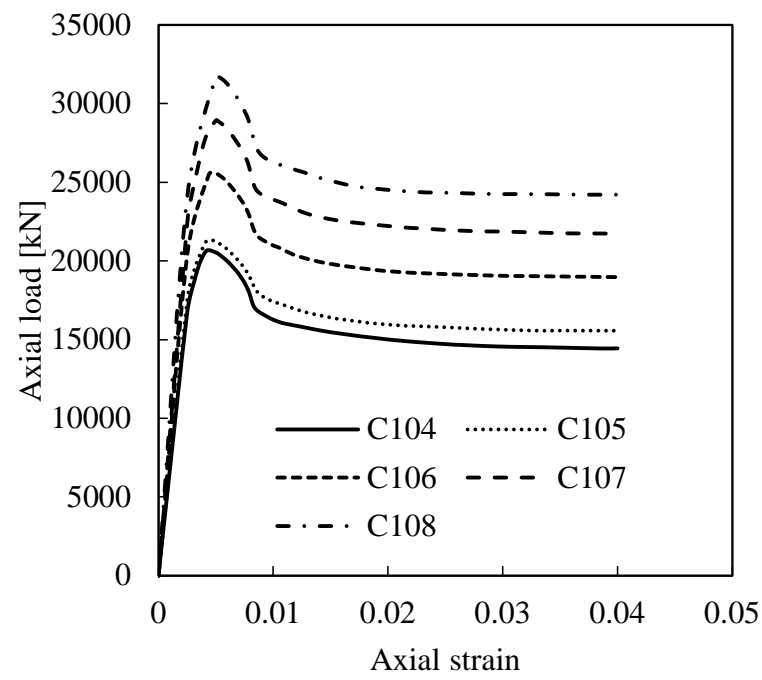

(b) C104-C108

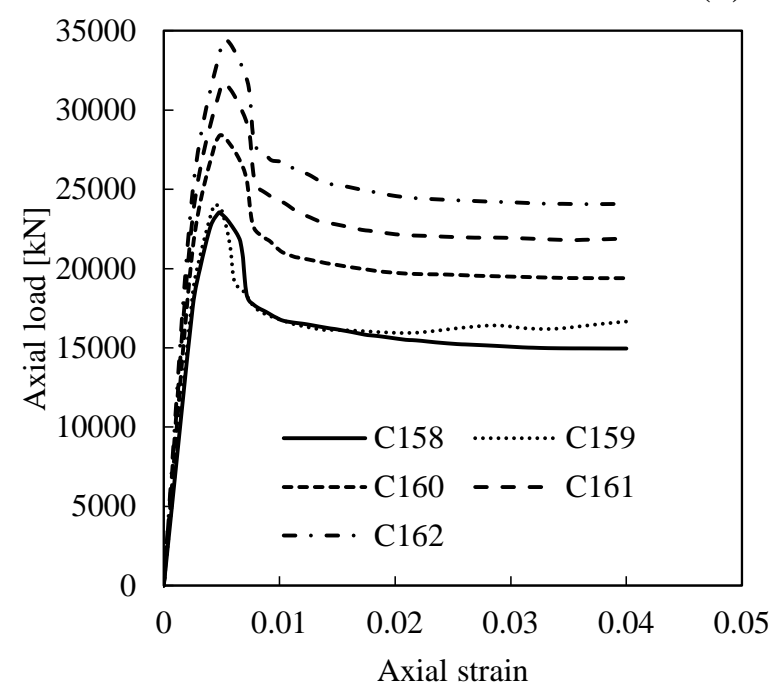

(c) C158-C162

Fig. 11: Axial load-strain curves for typical hexagonal CFST short columns

\subsection{Effects of concrete compressive strengths}

In this parametric study, three concrete compressive strengths $f_{c}^{\prime}$ were considered with values of 40, 65 and $80 \mathrm{MPa}$. According to the EN 1992-1-1 [31], the concrete is defined as 
high strength concrete (HSC) when $50 \mathrm{MPa}<f_{c}^{\prime} \leq 90 \mathrm{MPa}$. Therefore, group G1 is filled by NSC, while groups G2 and G3 are filled with HSC. The CCRs, defined in Eq. 14, are provided in Table 9 for the columns formed from steel tubes of 250MPa yield stress, while Table 10 shows those having the same $f_{c}^{\prime}$ of $65 \mathrm{MPa}$ but with different steel grades. From Table 9, it can be seen that the concrete bears higher contribution from the total load $\left(P_{u l, F E}\right)$ of the CFST columns with the increase in the $f_{c}^{\prime}$ value. On the contrary, the concrete contribution decreases when the yield stress of the steel material increases, as can be seen from Table 10. However, both tables show similar concrete effect by increasing the $D / t$ ratios. The results indicate that the concrete becomes more effective with increasing the $D / t$ ratios when $D$ is fixed. This is because the buckling capacity of the steel tube decreases significantly by making the steel cross-section more slender. On the opposite, increasing the $D / t$ ratios by increasing the diameter of the steel tube (see for example C6, C12 and C17) enlarges the concrete contribution mainly due to the increase in the concrete area within the column cross-section.

The effect of the $f_{c}^{\prime}$ value on the load-strain curves is presented in Fig. 12, which shows this effect for two sets of columns with different $D / t$ ratios. In Fig. 12(a), columns C50, C104 and C158 had $f_{c}^{\prime}$ values of 40, 65 and 80MPa, respectively, but all with $D / t=75$. Fig. 12(b) represents that relationships for columns C54, C108 and C162 filled with concrete of $f_{c}^{\prime}$ values of 40, 65 and 80MPa, respectively, but all with $D / t=37.5$. Within each figure, it can be noticed that varying the value of $f_{c}^{\prime}$ does not have any effect on the initial stiffness of the columns. The main differences in behaviour may be seen in between the points where the elastic limit finishes and the ultimate load is reached. In these behavioural stages, the stressstrain relationships takes the round shape for just for the columns filled with normal strength 
concrete (C50 and C54), while the columns filled with HSC are characterised with sharp transitional relationships followed with dramatic loss in the load carrying capacity. Additionally, it can be recognised that changing the concrete strength in the hexagonal CFST short columns seems not to have any effect on the residual strength remains after failure.

Fig. 13 shows the ultimate axial load of hexagonal CFST columns with the same diameters filled with different $f_{c}^{\prime}$ values, from which two $D / t$ ratios were only provided for the clearness of the presentation. The lines without markers belong for columns with $D / t$ ratios of 66.67, while those with markers are the columns with $D / t=28.57$. As can be seen, increasing the value of $f_{c}^{\prime}$ raises linearly the ultimate axial strengths of the columns, but the increase become larger for columns with less $D / t$ ratios (i.e. thicker tubes).

Table 9: CCRs for sample results with $f_{y}=250 \mathrm{MPa}$

\begin{tabular}{|c|c|c|c|c|c|c|c|c|c|}
\hline \multicolumn{4}{|c|}{ Cross-sectional dimensions } & \multicolumn{2}{|c|}{$\begin{array}{c}\text { G1-1: } \\
f_{c}^{\prime}=40 \mathrm{MPa}\end{array}$} & \multicolumn{2}{|c|}{$\begin{array}{c}\mathrm{G} 2-1: \\
f_{c}^{\prime}=65 \mathrm{MPa}\end{array}$} & \multicolumn{2}{|c|}{$\begin{array}{c}\text { G3-1: } \\
f_{c}^{\prime}=80 \mathrm{MPa}\end{array}$} \\
\hline$\underset{(\mathrm{mm})}{D}$ & $\underset{(\mathrm{mm})}{B}$ & $\begin{array}{c}t \\
(\mathrm{~mm})\end{array}$ & $\frac{D}{t}$ & No. & CCR & No. & CCR & No. & CCR \\
\hline \multirow{6}{*}{400} & \multirow{6}{*}{346} & 4.00 & 100.00 & C1 & 0.74 & C55 & 0.81 & C109 & 0.84 \\
\hline & & 6.00 & 66.67 & $\mathrm{C} 2$ & 0.67 & C56 & 0.76 & C110 & 0.79 \\
\hline & & 8.00 & 50.00 & C3 & 0.64 & C57 & 0.72 & C111 & 0.76 \\
\hline & & 10.00 & 40.00 & C4 & 0.62 & C58 & 0.69 & C112 & 0.73 \\
\hline & & 12.00 & 33.33 & C5 & 0.58 & C59 & 0.65 & C113 & 0.69 \\
\hline & & 14.00 & 28.57 & C6 & 0.53 & C60 & 0.61 & C114 & 0.64 \\
\hline \multirow{6}{*}{500} & \multirow{6}{*}{433} & 5.00 & 100.00 & C7 & 0.77 & C61 & 0.83 & C115 & 0.86 \\
\hline & & 6.00 & 83.33 & C8 & 0.73 & C62 & 0.81 & C116 & 0.84 \\
\hline & & 8.00 & 62.50 & C9 & 0.65 & C63 & 0.75 & C117 & 0.78 \\
\hline & & 10.00 & 50.00 & C10 & 0.65 & C64 & 0.73 & C118 & 0.76 \\
\hline & & 12.00 & 41.67 & C11 & 0.63 & C65 & 0.71 & C119 & 0.74 \\
\hline & & 14.00 & 35.71 & C12 & 0.61 & C66 & 0.69 & C120 & 0.72 \\
\hline \multirow{6}{*}{600} & \multirow{6}{*}{520} & 6.00 & 100.00 & C13 & 0.77 & C67 & 0.84 & C121 & 0.86 \\
\hline & & 8.00 & 75.00 & C14 & 0.71 & C68 & 0.79 & C122 & 0.82 \\
\hline & & 10.00 & 60.00 & C15 & 0.66 & C69 & 0.74 & C123 & 0.78 \\
\hline & & 12.00 & 50.00 & C16 & 0.65 & C70 & 0.73 & C124 & 0.76 \\
\hline & & 14.00 & 42.86 & C17 & 0.64 & C71 & 0.71 & C125 & 0.75 \\
\hline & & 16.00 & 37.50 & C18 & 0.57 & C72 & 0.65 & C126 & 0.69 \\
\hline
\end{tabular}


Table 10: CCRs for sample results with $f_{c}^{\prime}=65 \mathrm{MPa}$

\begin{tabular}{|c|c|c|c|c|c|c|c|c|c|}
\hline \multicolumn{4}{|c|}{ Cross-sectional dimensions } & \multicolumn{2}{|c|}{$\begin{array}{c}\text { G2-1: } \\
f_{y}=250 \mathrm{MPa} \\
\end{array}$} & \multicolumn{2}{|c|}{$\begin{array}{c}\mathrm{G} 2-2: \\
f_{y}=350 \mathrm{MPa}\end{array}$} & \multicolumn{2}{|c|}{$\begin{array}{c}\text { G2-3: } \\
f_{y}=450 \mathrm{MPa}\end{array}$} \\
\hline$\underset{(\mathrm{mm})}{D}$ & $\underset{(\mathrm{mm})}{B}$ & $\begin{array}{c}t \\
(\mathrm{~mm})\end{array}$ & $\frac{D}{t}$ & No. & CCR & No. & CCR & No. & CCR \\
\hline \multirow{6}{*}{400} & \multirow{6}{*}{346} & 4.00 & 100.00 & C55 & 0.81 & C73 & 0.79 & C91 & 0.75 \\
\hline & & 6.00 & 66.67 & C56 & 0.76 & C74 & 0.71 & C92 & 0.66 \\
\hline & & 8.00 & 50.00 & C57 & 0.72 & C75 & 0.67 & C93 & 0.63 \\
\hline & & 10.00 & 40.00 & C58 & 0.69 & C76 & 0.65 & C94 & 0.61 \\
\hline & & 12.00 & 33.33 & C59 & 0.65 & C77 & 0.62 & C95 & 0.59 \\
\hline & & 14.00 & 28.57 & C60 & 0.61 & C78 & 0.59 & C96 & 0.56 \\
\hline \multirow{6}{*}{500} & \multirow{6}{*}{433} & 5.00 & 100.00 & C61 & 0.83 & C79 & 0.79 & C97 & 0.75 \\
\hline & & 6.00 & 83.33 & C62 & 0.81 & C80 & 0.76 & C98 & 0.72 \\
\hline & & 8.00 & 62.50 & C63 & 0.75 & C81 & 0.68 & C99 & 0.63 \\
\hline & & 10.00 & 50.00 & C64 & 0.73 & C82 & 0.67 & C100 & 0.63 \\
\hline & & 12.00 & 41.67 & C65 & 0.71 & C83 & 0.66 & C101 & 0.62 \\
\hline & & 14.00 & 35.71 & C66 & 0.69 & C84 & 0.63 & C102 & 0.60 \\
\hline \multirow{6}{*}{600} & \multirow{6}{*}{520} & 6.00 & 100.00 & C67 & 0.84 & C85 & 0.80 & C103 & 0.77 \\
\hline & & 8.00 & 75.00 & C68 & 0.79 & C86 & 0.74 & C104 & 0.70 \\
\hline & & 10.00 & 60.00 & C69 & 0.74 & C87 & 0.68 & C105 & 0.63 \\
\hline & & 12.00 & 50.00 & C70 & 0.73 & C88 & 0.68 & C106 & 0.63 \\
\hline & & 14.00 & 42.86 & C71 & 0.71 & C89 & 0.66 & C107 & 0.62 \\
\hline & & 16.00 & 37.50 & C72 & 0.65 & C90 & 0.64 & C108 & 0.60 \\
\hline
\end{tabular}

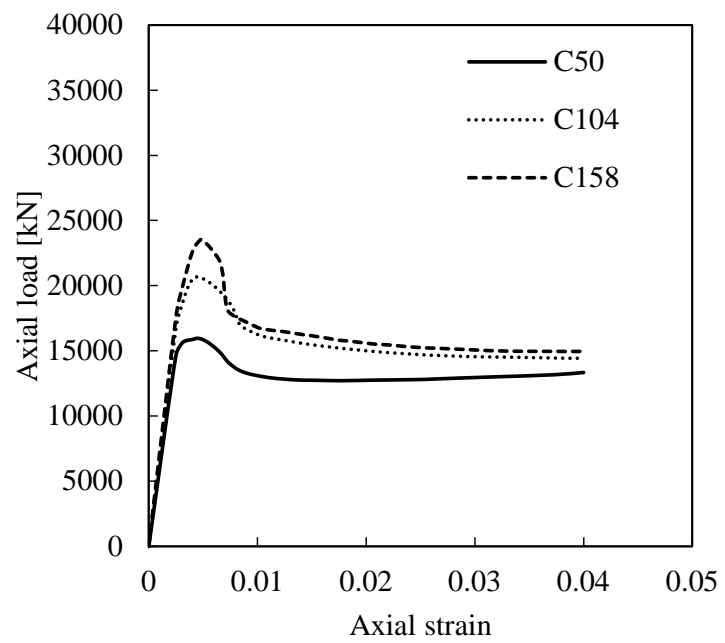

(a) $D / t=75$

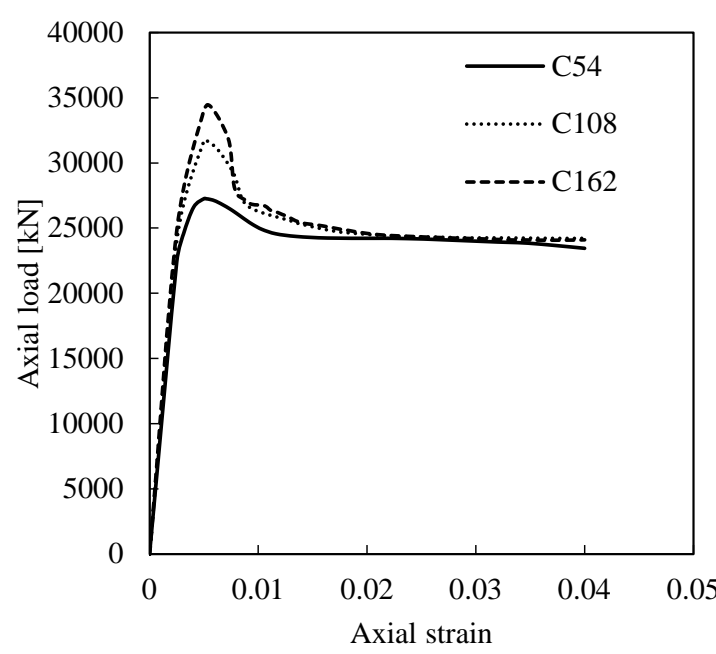

(b) $D / t=37.5$

Fig. 12: Axial load-strain curves for typical hexagonal CFST short columns showing the effect of the $f_{c}^{\prime}$ value 


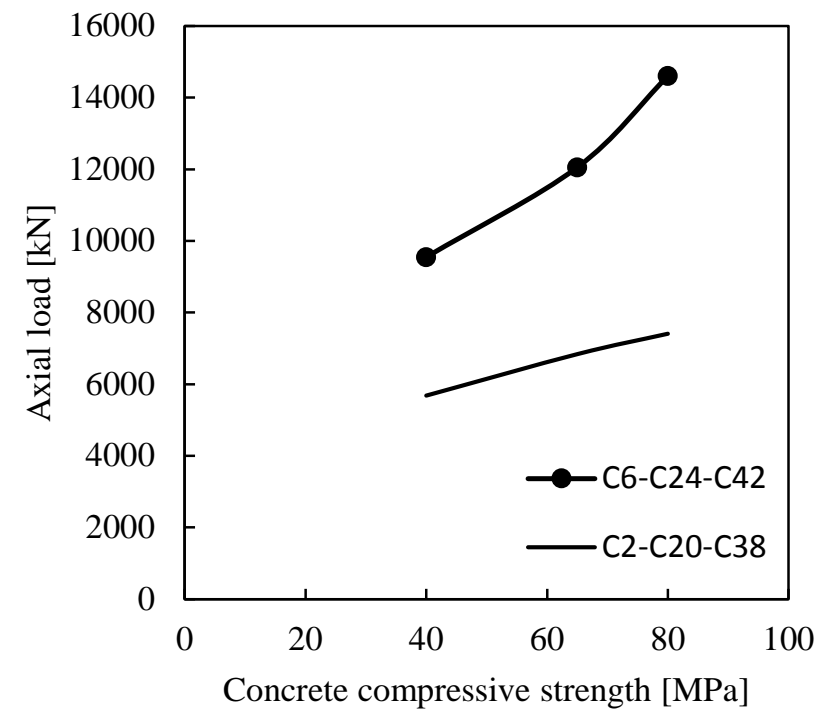

Fig. 13: Effects of concrete compressive strengths on the ultimate axial strengths of hexagonal CFST columns for $D=400 \mathrm{~mm}$

\subsection{Effects of steel yield strengths}

The effect of the yield strength $\left(f_{y}\right)$ value on the load-strain curves is presented in Fig. 14 . This figure provides this effect for two sets of columns with different the $D / t$ ratios. In Fig. 14(a), columns C8 C26 and C44 had $f_{y}$ values of 250, 350 and 450MPa, respectively, but all with $D / t=83.33$. Fig. 14(b) represents that relationships for columns C12, C30 and C48 filled with concrete of $f_{y}$ values of 250, 350 and 450MPa, respectively, but all with $D / t=35.71$. Within each figure, it can be noticed that varying the value of $f_{y}$ does not have any effect on the initial stiffness of the columns. The main differences in behaviour may be seen when the carrying load reaches the inelastic behavioural stage. By increasing the steel grade, column represents typical load-strain response but it is shifted upwards. Generally, the transition around the ultimate load of the column becomes sharper when the yield strength of the used steel increases. On the other hand, it becomes important to evaluate the additional axial compressive load carried by the current hexagonal CFST columns compared with the increased strength in the used grade. The percentage of increase of ultimate strength $P$ and 
yield stress of the steel material between two columns $\left(C_{i}\right.$ and $\left.C_{j}\right)$ were calculated using the following expressions. For group G1 as sample results, the values of these coefficients are given in Table 11, from which it can be noticed that columns $C_{i}$ are always those formed from steels of yielding stress of 250MPa.

$$
P_{j i}=\frac{P_{G j}-P_{G i}}{P_{G j}} \quad Y_{j i}=\frac{Y_{G j}-Y_{G i}}{Y_{G j}}
$$

Although the strengths of the columns, for the different $D / t$ ratios, increase with the increase in the $f_{y}$ values, the increase of the $f_{y}$ values is always higher than the increase of ultimate load of the columns. However, as the $D / t$ ratios decreases (by increasing the thickness $t$ ), the enhancement in the ultimate load becomes greater, but still it does not approach the increase in the yield stress of the material. So, it becomes economical to use higher steel grades with stocky hexagonal columns characterised by small $D / t$ ratios.

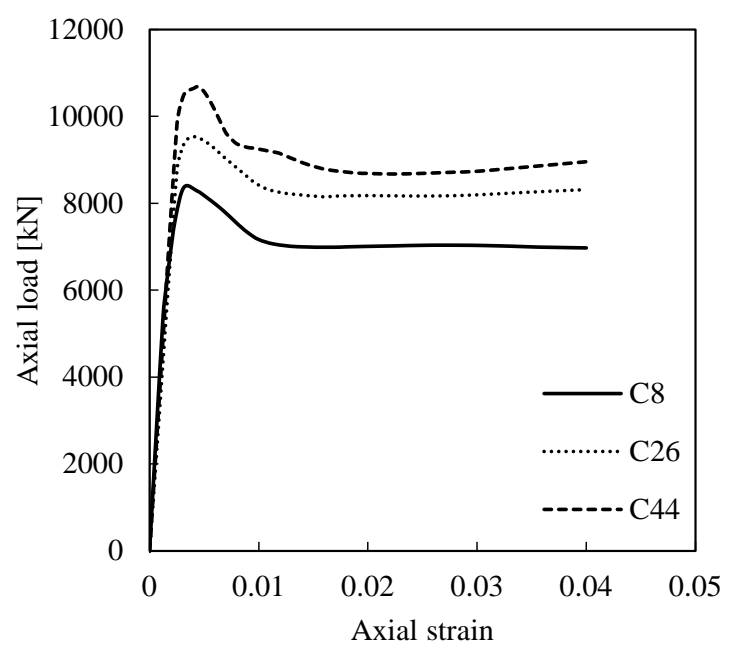

(a) $D / t=83.33$

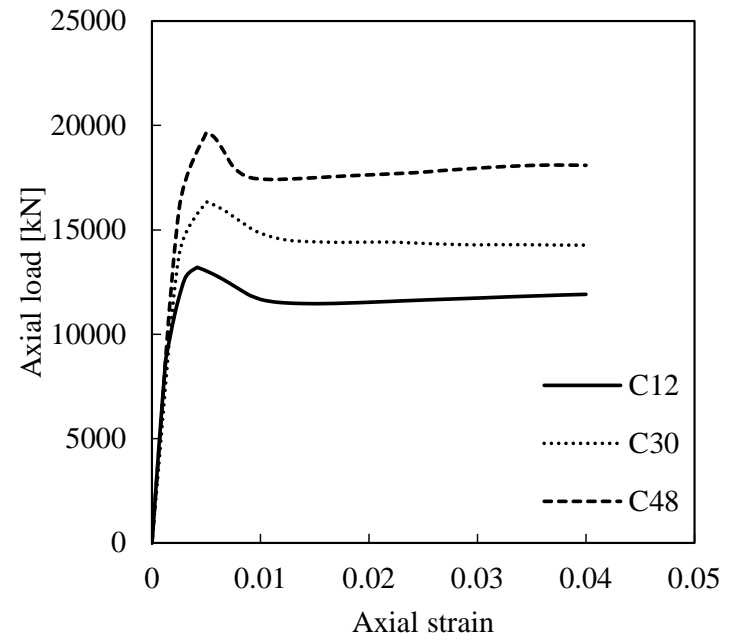

(b) $D / t=35.71$

Fig. 14: Axial load-strain curves for typical hexagonal CFST short columns showing the effect of the steel $f_{y}$ value 
Table 11: Variation of $P_{G i}$ and $Y_{j i}$ for group G1

\begin{tabular}{|c|c|c|c|c|c|c|c|c|}
\hline$D$ & $f_{y}=$ & 1: & G1- & $y=3$ & ИРa & & $f_{y}=$ & $\mathrm{MPa}$ \\
\hline$t$ & $C_{i}$ & $\begin{array}{c}P_{G i} \\
(\mathrm{kN})\end{array}$ & No. & $P_{j i}$ & $Y_{j i}$ & No. & $P_{j i}$ & $Y_{j i}$ \\
\hline 100.00 & C1 & 5176 & C19 & 0.11 & \multirow{18}{*}{0.29} & C37 & 0.20 & \multirow{18}{*}{0.44} \\
\hline 66.67 & C2 & 5681 & C20 & 0.13 & & C38 & 0.23 & \\
\hline 50.00 & C3 & 6731 & C21 & 0.16 & & C39 & 0.28 & \\
\hline 40.00 & C4 & 7895 & C22 & 0.18 & & C40 & 0.31 & \\
\hline 33.33 & C5 & 8791 & C23 & 0.20 & & C41 & 0.33 & \\
\hline 28.57 & C6 & 9548 & C24 & 0.21 & & C42 & 0.35 & \\
\hline 100.00 & C7 & 8089 & C25 & 0.11 & & C43 & 0.20 & \\
\hline 83.33 & C8 & 8369 & C26 & 0.12 & & C44 & 0.22 & \\
\hline 62.50 & C9 & 8505 & C27 & 0.12 & & C45 & 0.22 & \\
\hline 50.00 & C10 & 10511 & C28 & 0.16 & & C46 & 0.28 & \\
\hline 41.67 & C11 & 11732 & C29 & 0.20 & & C47 & 0.32 & \\
\hline 35.71 & C12 & 13202 & C30 & 0.19 & & C48 & 0.33 & \\
\hline 100.00 & C13 & 11651 & C31 & 0.11 & & C49 & 0.20 & \\
\hline 75.00 & C14 & 12355 & C32 & 0.13 & & C50 & 0.23 & \\
\hline 60.00 & C15 & 12802 & C33 & 0.13 & & C51 & 0.24 & \\
\hline 50.00 & C16 & 15141 & C34 & 0.16 & & C52 & 0.28 & \\
\hline 42.86 & C17 & 16925 & C35 & 0.18 & & C53 & 0.31 & \\
\hline 37.50 & C18 & 18459 & C36 & 0.19 & & C54 & 0.32 & \\
\hline
\end{tabular}

\section{SUGGESTED DESIGN MODEL AND VALIDATION}

This section presents a new equation to design regular hexagonal CFST short columns in compression that intends to improve predictions of existing models assessed in Section 2. In particular, an equation that provides a better fit to the observed response over a wider range of $D / t$ ratios is sought. This is achieved using the numerical data generated above and considering the superposition model that combines the strengths carried by both the hexagonal steel tube and the concrete core. The contribution of the concrete core in the overall strength of the CFST short columns considers its enhanced strength due to the confinement effect by using the $f_{r p}$ formula proposed previously in Eq. (11). Similar design models following this approach have been proposed in literature [27-28]. Accordingly, the current suggested design model for hexagonal CFST short columns in compression is given in Eq. (16).

$$
P_{u l, \text { Sug }}=\left(\gamma_{c} f_{c}^{\prime}+4.1 \times f_{r p}\right) A_{c}+f_{y} A_{s}
$$


As it is observed, this design model assumes the yielding of the steel tube as the upper limit for the steel contribution in the overall strength of the composite column. Table 12 provides the mean and the COV (coefficient of variation) of the predicted to numerical ratios for the three design models assessed in Section 2 and that proposed herein given in Eq. (16). The results show that all models are safe with predicted to numerical ratios below 1.0. Yu et al [12] $\left(P_{u l, Y u}\right)$ and EN 1994-1-1 [13,17] $\left(P_{u l, \mathrm{Rec}, E C 4}\right)$ models are the most conservative with mean ratios far below 1.0. Ding et al [16] model ( $\left.P_{u l, D i n g}\right)$ and the proposed model in Eq. (16) $\left(P_{u l, S u g}\right)$ are the most efficient methods with mean ratio values of 0.99 and 0.98 , respectively, though Eq. (16) provides a significant lower COV of 0.019 compared to that achieved by Ding et al [16] of 0.085. Therefore, the proposed model in the present research to predict ultimate axial strength given in Eq. (16) is more consistent and reliable. Predicted strengths $\mathrm{P}_{\mathrm{u}}$ by Refs. [12], [13, 17], [16] and Eq. (16) over strengths achieved by the numerical models $\mathrm{P}_{\mathrm{u}, \mathrm{FE}}$ are plotted against $D / t$ ratios for group G1-3 (see Table 4) in Fig.15 where trend lines are also included. This figure shows that the ratio $\mathrm{P}_{\mathrm{u}} / \mathrm{P}_{\mathrm{u}, \mathrm{FE}}$ for the existing design models proposed by Yu et al. [12], Xu et al. [13, 17] and Ding et al. [16] increases with increasing $D / t$ ratios whereas the suggested design model given in Eq. (16), with a significantly flatter trend line, provides more accurate results over the full range of $D / t$ ratios. Finally, the suggested design model is validated against the experimental results [15-16] available in the literature for the regular hexagonal CFST short columns in compression. This validation is shown in Table 2 where the mean value of the predicted strength $P_{u l, s u g}$ relative to the experimental strengths $P_{u l \text { Exp }}$ is 0.96 and associated COV of 0.096 with a few over predictions for small-diameter specimens tested by Evirgen et al. [15]. This demonstrates that the proposed model yields better predictions than existing models [12], [13, 17] and [16] leading to a more reliable, economic and sustainable design, and therefore the main goal of 
this research is achieved. Additionally, Fig. 15, compared with Fig. 3, enables to confirm that the proposed design model $P_{u l, \text { sug }}$ given in Eq. (16) provides accurate results over the entire $D / t$ ratio.

Table 12: Mean and standard deviation of the different design models

\begin{tabular}{|c|c|c|c|c|}
\hline \multirow{2}{*}{ Indices } & $\frac{P_{u l, Y u}}{P_{u l, F E}}$ & $\frac{P_{u l, \text { Rec }, \text { EC } 4}}{P_{u l, F E}}$ & $\frac{P_{u l, \text { ing }}}{P_{u l, F E}}$ & $\frac{P_{u l, \text { Sug }}}{P_{u l, F E}}$ \\
\hline Mean & 0.85 & 0.90 & 0.99 & 0.98 \\
\hline COV & 0.055 & 0.102 & 0.085 & 0.019 \\
\hline
\end{tabular}

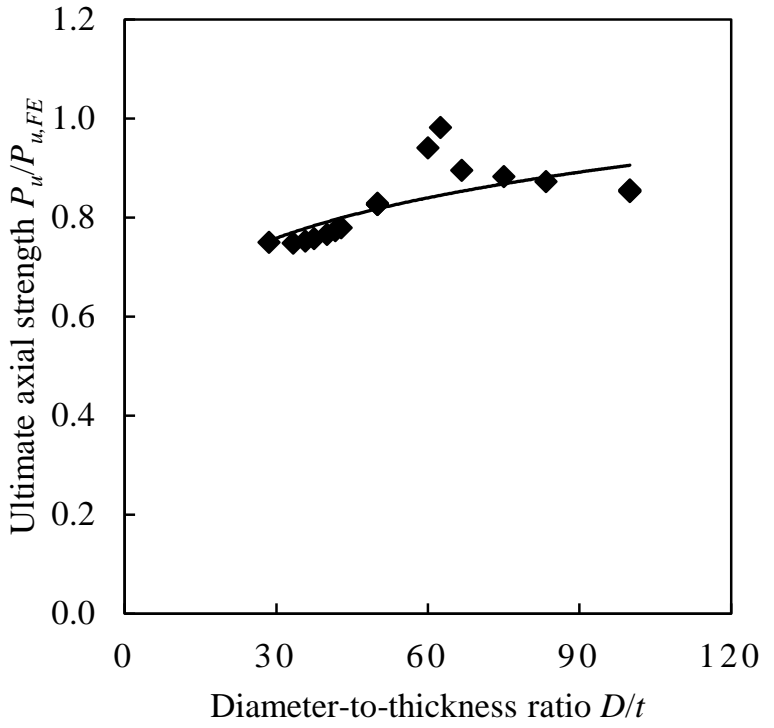

(a) Yu et al. [12]

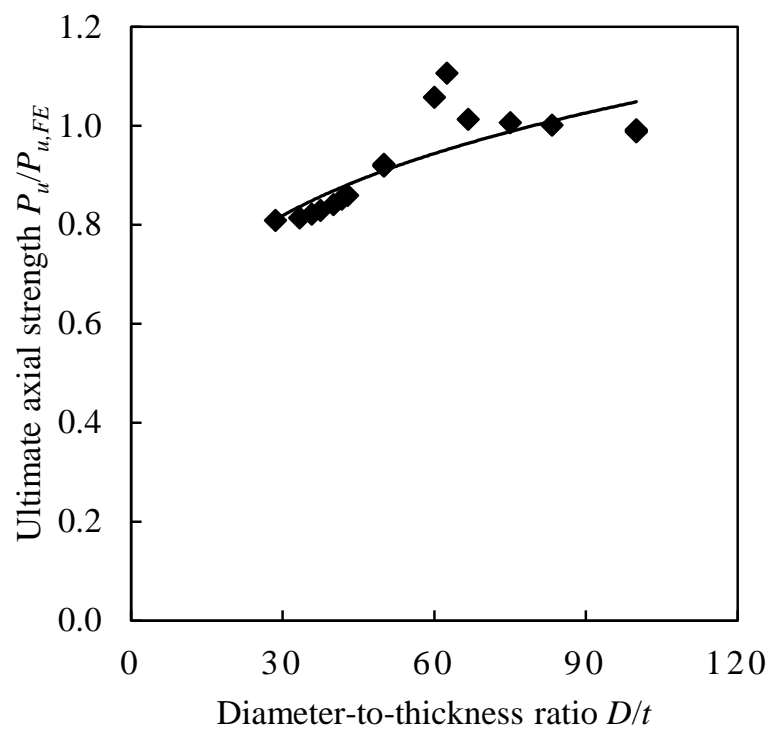

(c) Ding et al. [16]

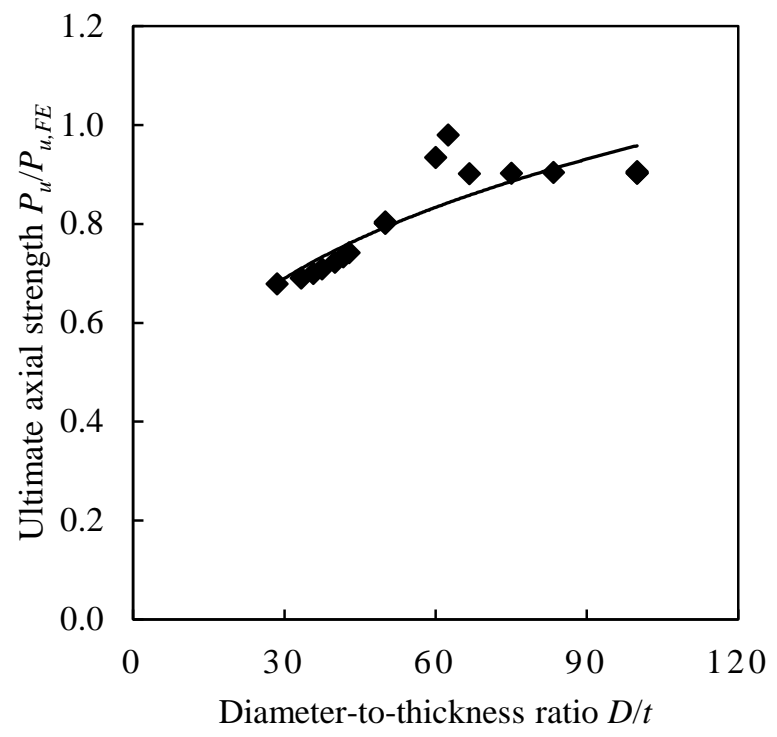

(b) Eurocode $4[13,17]$

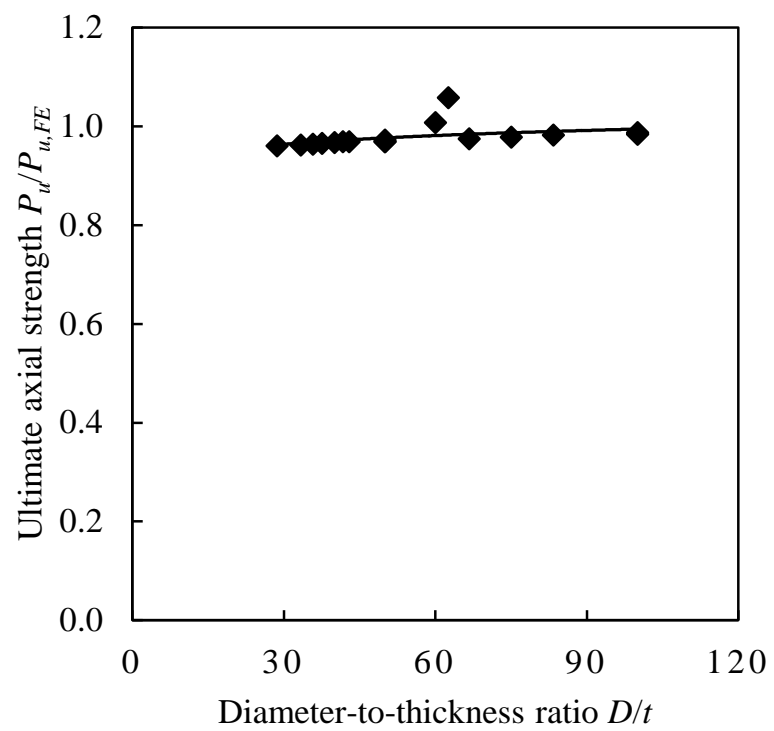

(d) Suggested design model - Eq. (16)

Fig. 15: Comparison of design and FE ultimate axial loads for hexagonal CFST short columns with different $D / t$ ratios for group G1-3 


\section{CONCLUSIONS}

Based on the current investigation, the following conclusions are drawn:

1. There is little research covering hexagonal CFST columns and therefore the need to explore this field has been identified. Such research need has been addressed in the present investigation theoretically and numerically.

2. Experiments available in the literature $[13,16]$ have been used to develop, calibrate and validate a comprehensive numerical model and parametric studies have been subsequently carried out.

3. The strength of a CFST in compression $P_{u l, F E}$ has been compared against the strength of the steel tube alone by defining a strength index (SI) taken as the strength of the CFST column $\left(P_{u l, F E}\right)$ and divided by the strength of the hexagonal steel tube alone $\left(P_{u l, F E, S T}\right)$. The comparison was based on numerical results and revealed that considerable benefits can be achieved by the composite solution.

4. It was noticed that the SI increases with decreasing diameter-to-thickness $(D / t)$ ratio, indicating that the composite action is more significant for slender cross-section columns.

5. The results showed that the axial load-strain curves display a typical ascending and postfailure descending response for the columns with different $D / t$ ratios. It was observed that the more slender the cross-section of CFST short columns is (i.e increasing $D / t$ ratio), the more significant the ultimate axial strength reduces regardless the value of the concrete compressive strength $f_{c}^{\prime}$ while the stiffness reduces slightly. Additionally, the load-strain curves showed a considerable residual strength that remains after failure.

6. It was found that increasing the value of $f_{c}^{\prime}$ increases linearly the ultimate axial strength of the composite columns, but the increase becomes more significant for stocky crosssections. (i.e columns with lower $D / t$ ratios). 
7. The results indicated that slender cross-section CFST columns benefit more from the composite action than stocky ones. This is because the buckling capacity of the steel tube decreases significantly when making the steel cross-section more slender.

8. It was observed that higher steel grades improve the resistance of CFST column and the stockier the cross-sections is (for lower $D / t$ ratios achieved by increasing the thickness $t$ ), the more significant the enhancement is. Therefore, it becomes economical to use higher steel grades with stocky hexagonal columns characterised by small $D / t$ ratios.

9. A new formula to determine the lateral confining pressure for regular hexagonal CFST short columns in compression has been proposed and given in Eq. (11).

10. A new design model for regular hexagonal CFST short columns in compression that provides more reliable and accurate predictions over the full range of $D / t$ ratios than available models has been proposed. The model has been validated against experiments from literature $[15,16]$ and demonstrated that better predicts resistances than the available models proposed by Yu et al. [12], EN 1994-1-4 revised by Xu et al. [13, 17] and Ding et al. [16]; especially for large-diameter columns.

This research has contributed to acquire in depth understanding of the behaviour of regular hexagonal CFST short columns with large-diameter in compression. Although the proposed models have been validated in the present study, further evaluation is needed hence, it is recommended to continue testing to broaden the pool of experimental data. Additionally, an investigation into the behaviour of intermediate-length and long columns as well as beamcolumns should also be conducted in future. Further study is required to propose a passive confinement model for the concrete core in hexagonal CFST columns, which accounts for the effects of steel strain hardening on the confinement. 


\section{ACKNOWLEDGMENTS}

The authors would like to acknowledge Dr A. Tuncan, Dr K. Taskin and especially Mr. Burak Evirgen for sharing their relevant test data which assisted in developing the research of this article.

\section{REFERENCES}

[1] Chacón, R. "Circular Concrete-Filled Tubular Columns: State of the Art Oriented to the Vulnerability Assessment", The Open Civil Engineering Journal, Vol. 9, pp. 249-259, 2015.

[2] Han, L-H., Wei, L., Bjorhovde, R., "Developments and Advanced Applications of Concrete-Filled Steel Tubular (CFST) Structures: Members", Journal of Constructional Steel Research, Vol. 100, pp. 211-228, 2014.

[3] Liew, J.Y.R., Xiong, M.X., Xiong, D.X., "Design of High Strength Concrete Filled Tubular Columns for Tall Buildings", Journal of high-rise buildings, Vol. 3, pp. 1-7, 2014.

[4] Roseline, K., Tensing, D., "State of The Art Report on Steel-Concrete Infilled Composite Column", International Journal of Scientific \& Engineering Research, Vol. 4, pp. 677-684, 2013.

[5] Patel, V.I., "Nonlinear Inelastic Analysis of Concrete-Filled Steel Tubular Slender Beam-Columns", Ph.D. thesis, Victoria University, Australia, 2013.

[6] Hassanein, M.F., "Behavior of Composite Columns: Concrete-Filled Hollow-Section Stiffened Steel Columns", Ph.D. thesis, Tanta University, Tanta, Egypt, 2009.

[7] Shanmugam, N.E., Lakshmi, B., "State of the Art Report on Steel-Concrete Composite Columns", Journal of Constructional Steel Research, Vol. 57, pp. 1041-1080, 2001. 
[8] Yang, H., Lam, D., Gardner, L., "Testing and Analysis of Concrete-Filled Elliptical Hollow Sections", Engineering Structures, Vol. 30, pp. 3771-3781, 2008.

[9] Kitada, T., "Ultimate Strength and Ductility of State-of-The-Art Concrete-Filled Steel Bridge Piers in Japan", Engineering Structures, Vol. 20, pp. 347-354, 1998.

[10] Chacón, R., Mirambell, E., Real, E., "Strength and Ductility of Concrete-Filled Tubular Piers of Integral Bridges", Engineering Structures, Vol. 46, pp. 234-246, 2013.

[11] Bergmann, R., Matsui, C., Meinsma, C., Dutta, D., "Design Guide for Concrete Filled Hollow Section Columns under Static and Seismic Loading", CIDECT, Verlag TUD Rheinland, Koln, 1995.

[12] Yu, M., Zha, X., Ye, J., Li, Y., "A Unified Formulation for Circle and Polygon Concrete-Filled Steel Tube Columns under Axial Compression", Engineering Structures, Vol. 49, pp. 1-10, 2013.

[13] Xu, W., Han, L-H., Li, W., "Performance of Hexagonal CFST Members under Axial Compression and Bending", Journal of Constructional Steel Research, Vol. 123, pp. 162-175, 2016.

[14] Tomii, M., Yoshimura, K., Morishita, Y., "Experimental Studies on Concrete Filled Steel Tubular Stub Columns under Concentric Loading", In: International Colloquium on Stability of Structures under Static and Dynamic Loads: Washington, DC, pp. 718741, 1977.

[15] Evirgen, B., Tuncan, A., Taskin, K., "Structural Behaviour of Concrete Filled Steel Tubular Sections (CFT/CFST) under Axial Compression", Thin-Walled Structures, Vol. 80, pp. 46-56, 2014.

[16] Ding, F-X., Li, Z., Cheng, S., Yu, Z-W., "Composite Action of Hexagonal ConcreteFilled Steel Tubular Stub Columns under Axial Loading", Thin-Walled Structures, Vol. 107, pp. 502-513, 2016. 
[17] EN 1994-1-1: Eurocode 4. Design of composite steel and concrete structures. Part 1.1, General rules and rules for buildings. European Committee for Standardization, 2004.

[18] ABAQUS Standard, User's Manual The Abaqus Software is a product of Dassault Systèmes Simulia Corp., Providence, RI, USA Dassault Systèmes, Version 6.8, USA, 2008.

[19] Zhu, L., Ma, L., Bai, Y., Li, S., Song, Q., Wei, Y., Zhang, L., Zhang, Z., Sha, X., "Large Diameter Concrete-Filled High Strength Steel Tubular Stub Columns under Compression", Thin-Walled Structures, Vol. 108, pp. 12-19, 2016.

[20] Tao, Z., Wang, Z.B., Yu, Q., "Finite element modelling of concrete-filled steel stub columns under axial compression", Journal of Constructional Steel Research, Vol. 89, pp. 121-131, 2013.

[21] Liang, Q. Q., "Performance-Based Analysis of Concrete-Filled Steel Tubular BeamColumns, Part I: Theory and Algorithms", Journal of Constructional Steel Research, Vol. 65, Issue 2, pp. 363-372, 2009.

[22] Yu, T., Teng, J.G., Wong, Y.L., Dong, S.L., "Finite Element Modeling of Confined Concrete-I: Drucker-Prager Type Plasticity Model", Engineering Structures, Vol. 32, pp. 665-679, 2010.

[23] Mander, J. B., Priestly, M. N. J. and Park, R. "Theoretical Stress-Strain Model for Confined Concrete", Journal of Structural Engineering, ASCE, Vol. 114, Issue 8, pp. 1804-1826, 1988.

[24] ACI 318-11. Building code requirements for reinforced concrete. ACI Committee 318, Detroit (MI), 2011.

[25] Liang, QQ., Fragomeni, S., "Nonlinear Analysis of Circular Concrete-Filled Steel Tubular Short Columns under Axial Loading", Journal of Constructional Steel Research, Vol. 65(12), pp. 2186-2196, 2009. 
[26] Liang, Q.Q., Patel, V.I., Hadi, M.N.S., "Biaxially Loaded High-Strength ConcreteFilled Steel Tubular Slender Beam-Columns, Part I: Multiscale Simulation", Journal of Constructional Steel Research, Vol. 75, pp. 64-71, 2012.

[27] Hassanein, M.F., Kharoob O.F., Gardner, L., "Behaviour and Design of Square Concrete-Filled Double Skin Tubular Columns with Inner Circular Tubes", Engineering Structures, Vol. 100, pp. 410-424, 2015.

[28] Hassanein, M.F., Kharoob O.F., Liang, Q.Q., "Circular Concrete-Filled Double Skin Tubular Short Columns with External Stainless Steel Tubes Under Axial Compression", Thin-Walled Structures, Vol. 73, pp. 252-263, 2013.

[29] Hu, H.T., Huang, C.S., Wu, M.H., Wu, Y.M., "Nonlinear Analysis of Axially Loaded Concrete-Filled Tube Columns with Confinement Effect", Journal of Structural Engineering, ASCE, Vol. 129(10), pp. 1322-1329, 2003.

[30] Ellobody, E., Young, B., Lam, D., "Behaviour of Normal and High Strength ConcreteFilled Compact Steel Tube Circular Stub Columns", Journal of Constructional Steel Research, Vol. 62, pp. 706-715, 2006.

[31] EN 1992-1-1: Eurocode 2. Design of concrete structures. Part 1-1. General rules and rules for, buildings. European Committee for Standardization, 2004. 